Pacific Northwest

National Laboratory

Operated by Battelle for the

U.S. Department of Energy

\section{Analysis of Potential Free-Rider Eligibility for a Proposed Commercial Building Lighting Tax Deduction}

\author{
D. W. Winiarski \\ E. E. Richman \\ R. Biyani
}

September 2004 


\title{
DISCLAIMER
}

This report was prepared as an account of work sponsored by an agency of the United States Government. Neither the United States Government nor any agency thereof, nor Battelle Memorial Institute, nor any of their employees, makes any warranty, express or implied, or assumes any legal liability or responsibility for the accuracy, completeness, or usefulness of any information, apparatus, product, or process disclosed, or represents that its use would not infringe privately owned rights. Reference herein to any specific commercial product, process, or service by trade name, trademark, manufacturer, or otherwise does not necessarily constitute or imply its endorsement, recommendation, or favoring by the United States Government or any agency thereof, or Battelle Memorial Institute. The views and opinions of authors expressed herein do not necessarily state or reflect those of the United States Government or any agency thereof.

\author{
PACIFIC NORTHWEST NATIONAL LABORATORY \\ operated by \\ BATTELLE \\ for the \\ UNITED STATES DEPARTMENT OF ENERGY \\ under Contract DE-AC06-76RL01830
}

Printed in the United States of America

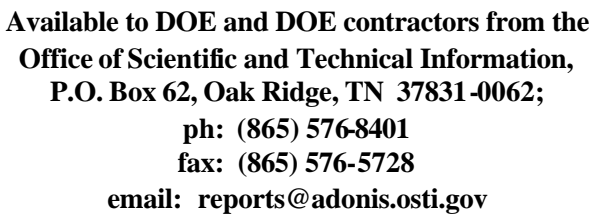

Available to the public from the National Technical Information Service, U.S. Department of Commerce, 5285 Port Royal Rd., Springfield, VA 22161 ph: (800) 553-6847 fax: $(703) 605-6900$

email: orders@ntis.fedworld.gov online ordering: http://www.ntis.gov/ordering.htm (3) This document was printed on recycled paper. 


\title{
Analysis of Potential Free-Rider Eligibility for a Proposed Commercial Building Lighting Tax Deduction
}

\author{
D. W. Winiarski \\ E. E. Richman \\ R. Biyani
}

September 2004

Prepared for

the U.S. Department of Energy Office of Building Technologies under Contract DE-AC06-76RL01830

Pacific Northwest National Laboratory

Richland, Washington 99352 


\section{Summary}

The report provides estimates of the potential volume of "free riders", in terms of both eligible square footage and associated available tax deductions, in a proposed commercial building lighting tax amendment to the 2003 Energy Bill. Determination of the actual tax rate for businesses and how the amendment may impact tax revenue collected by the treasury is beyond the scope of this effort. Others, such as the Treasury itself, are best equipped to make their own estimates of the eventual impact based on the total deductions available to taxable entities.

Free riders are defined as commercial building construction that would be eligible to apply for the tax deduction, but whose construction is not necessarily altered because of the availability of the tax deduction. Based on the analysis presented in this report, the estimate of the value of tax deductions available to free riders will be approximately $\$ 59$ million dollars per year for approximately $6 \%$ of new taxable floor space over the period from 2004 through 2007 after accounting for meeting both the LPD and controls requirements (including bi-level switching requirements) outlined in the proposed amendment. This estimate represents free riders that would likely not be required to do anything to achieve the deduction specified in the amendment. Based on the analysis presented, $20 \%$ to $25 \%$ of the new construction floor space in 2004 through 2007 would meet LPD requirements of the amendment. If LPD requirements were the only consideration, this would result in available tax deduction of between \$231 to \$280 million dollars per year for the period 2004 through 2007. This higher value could be considered an upper bound that represents free riders that may already have achieved the LPD requirements for the tax deduction and much of the associated energy savings (from the reduction in lighting power density) but would need to make some additional controls changes to be eligible for the deduction. These estimates reflect taxable new construction only and do not address building renovations that might also apply for the tax deduction.

The proposed tax deduction would be provided to commercial buildings constructed in the period from 2004 through 2007 whose installed lighting power densities are more than $25 \%$ below those required by ANSI/ASHRAE/IESNA 90.1-2001 levels (ASHRAE 90.1-2001). For warehouse buildings, the installed lighting power density must be 50\% below the 90.1-2001 levels. For all building types but warehouse, the tax deduction would be applied on a sliding scale starting at $\$ 0.375$ for achieving a $25 \%$ reduction in lighting power densities and going to a full $\$ 0.75 /$ sf deduction for buildings achieving a $40 \%$ reduction in lighting power densities.

The analysis used to derive the free-rider estimates looked at the known factors that may contribute to meeting the requirements of the proposed tax deduction amendment. This involves both the lighting power densities associated with current lighting practice in commercial buildings as well as the impact of the introduction of new building codes requiring lighting power densities lower than those prescribed in ASHRAE 90.1-2001. Other factors affecting the ability to meet the requirements for the tax deduction include complying with the lighting control requirements of the ASHRAE/ 90.1-2001 standard, installing bi-level switching, and meeting the current minimum IESNA illuminance recommendations. These factors can be represented by the following mathematical representations of the major paths to free riders. The first free-rider path is based on current typical lighting design practice:

Current-practice Free-rider square footage $=$ LPD-CP x ContComp x BiLevComp x IllumComp 
where:

LPD-CP = the effective square footage across the Nation that could be eligible for the tax deduction at full deduction value based solely on current LPD practice

ContComp $\quad=$ expected compliance with 90.1-2001 control requirements for lighting systems

BiLevComp $=$ expected compliance with the bilevel switching requirement

IllumComp $=$ expected compliance with the recommended illuminance requirements.

Some data is available from the National Commercial Construction Characteristics $\left(\mathrm{NC}^{3}\right)^{\mathrm{a}}$ data set developed at Pacific Northwest National Laboratories (PNNL) to estimate the percentage of commercial floor area under construction across the Nation that currently incorporates lighting power densities that meets the LPD tax deduction requirement. Applying appropriate national weighting factors to these data produces an estimated effective current-practice free-rider square footage percentage of $17.4 \%$ from LPD levels (LPD-CP) alone. This value is considered an upper bound because it does not include effects of other factors that may inhibit complete compliance with tax deduction code requirements. Current practice data suggesting the fraction of buildings whose lighting design would comply with the 90.1-2001 lighting control requirements is not available, but incorporation of limited current-practice data regarding the BiLevComp parameter reduces the estimate of free-rider floor space to approximately $4 \%$. However, we recognize that the incremental cost to only incorporate bi-level switching may be less than a complete lighting redesign to provide the required LPD levels in addition to the bi-level and other control requirements. The value of the deduction may encourage builders to incorporate these bi-level controls.

This revised percentage of free riders could further be modified by the remaining factors of compliance with lighting controls (ContComp) and illuminance levels (IllumComp) if data was available for these factors.

The second free-rider path is based on expected code adoptions:

Code Adoption Free-rider square footage = LPD-CA x STNDComp x BiLevComp x IllumComp x $k_{\text {adj }}$ where:

LPD-CA = the effective square footage across the Nation that could be eligible for the tax deduction at full deduction value based solely on code adoption LPD levels. This factor incorporates the varying expected code adoption dates for the major national energy codes.

STNDComp = expected compliance with 90.1-2001 lighting requirements. This Factor accounts for the fact that compliance with standards is less than $100 \%$.

BiLevComp $=$ expected compliance with the bilevel switching requirement

\footnotetext{
${ }^{\mathrm{a}}$ National Commercial Construction Characteristics Database $\left(\mathrm{NC}^{3}\right)$, an internal PNNL database of nationwide commercial construction energy-related characteristics.
} 
IllumComp $=$ expected compliance with the recommended illuminance requirements.

$\mathrm{k}_{\mathrm{adj}}=$ (total construction square footage - current-practice free-rider square footage) / total construction square footage. This adjustment factor accounts for the current practice free riders who are already exceed any code-driven requirements.

This data shows that in isolation, code adoption to meet the tax deduction LPD level requirements would be expected to impact approximately $2.8 \%$ of new construction in 2004, growing to $7.8 \%$ in 2007 (after accounting for current-practice free riders with LPDs below that required by new building codes). This value is also likely an upper bound because actual code adoption and actual code enforcement across the Nation are not $100 \%$. While a significant and growing fraction of the floor space would be required by code to meet the 90.1-2001 lighting controls between 2004 and 2007, only approximately 6\% of the total floor space under construction is expected to meet LPD requirements of the tax deduction as well as incorporate both the 90.1-2001 lighting controls and bilevel switching controls. The amount of floor space required by code to meet all three requirements of the tax deduction (LPD, 2001 lighting controls, and bi-level switching) was estimated at near 1\% or less for the period from 2004 to 2007. 


\section{Table of Contents}

Summary .................................................................................................................................. iii

Background....................................................................................................................................... 1

Principal Causes of LPD Free Riders ................................................................ 3

Analysis of Code-Driven LPD Free Riders ....................................................... 5

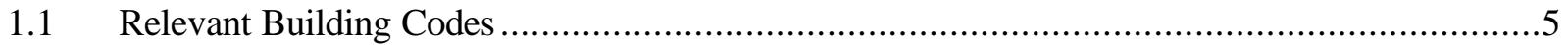

1.2 Estimating the fraction of new construction floor space driven by code to be eligible for a tax deduction

1.3 Estimating the dollar value of tax deductions available to code-driven free riders.....................8

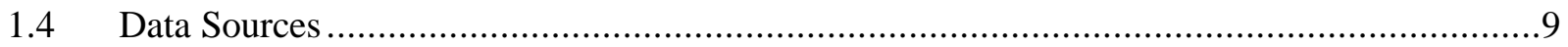

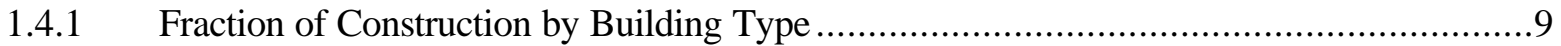

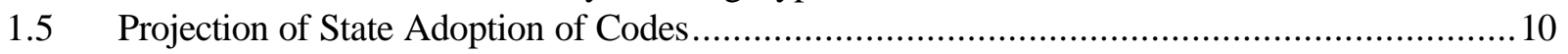

1.6 Commercial Construction Estimates by State ............................................................. 10

1.7 Results of Code-Driven Free-Rider Analysis .................................................................. 11

2.0 Current Lighting Practice Free Riders ............................................. 15

$2.1 \quad$ Analysis of Current-Practice Free Riders.............................................................. 16

2.1.1 National Commercial Construction Characteristics Database $\left(\mathrm{NC}^{3}\right)$ Data Source ............16

2.1.2 Other Data Sources................................................................................. 17

2.2 Results of Current-Practice Free-Rider Analysis ........................................................... 18

3.0 Combining LPD Code Driven and Current-Practice Free

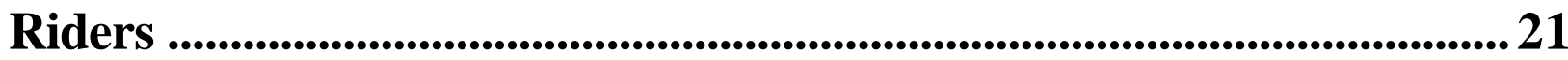

4.0 Impact of Other Requirements for the Tax Deduction...............23

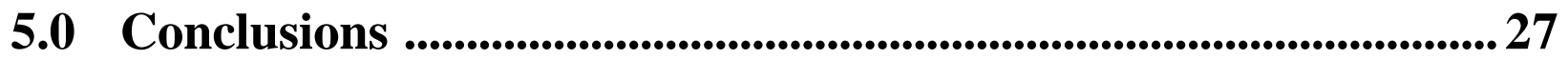

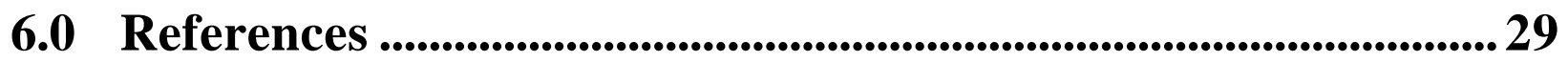

Appendix A National Energy Standard LPD Development ........... A.1 Appendix B Distributions of Current Practice Data.......................... B.1 Appendix C Projected New Floor Space by State ................................ C.1 Appendix D Other Current Practice Data Sources............................. D.1 


\section{Figures}

1. Comparison of LPD requirements between 90.1-1989 and 90.1-1999/2001_...............................6

2. Taxable Floor Space Fraction by Building Code (defined by LPD equivalence)..............................11

3. Average LPD Change for 90.1-2001 vs 90.1-2004 for Taxable Floor Space................................. 12

4. Fraction of Taxable New Construction Floor Space Eligible for Tax Deduction by Year through Code

Compliance (assumes 100\% code compliance) ......................................................... 13

5. Value of Tax Deduction Available to Free Riders from Building Codes (new construction only).......14

6. New Construction Floor Space Eligible for Tax Deduction $\left(\mathrm{NC}^{3}\right.$ data set).................................. 19

\section{Tables}

1. National Commercial Construction Floor Space Weighting by Building Category..........................9

2. Fraction of Buildings Eligible for Tax Deduction by $\mathrm{Nc}^{3}$ Data Set.............................................. 18 


\section{Background}

The U.S. DOE Office of Building Technologies made a request of $\mathrm{PNNL}^{\mathrm{b}}$ staff to provide an estimate of the number of potential "free riders" for a tax deduction proposed in amendment to the 2003 Draft Senate Energy Bill Legislation. The amendment modifies draft language for a commercial building energy tax deduction.

The draft Energy Bill calls for a tax deduction for commercial buildings whose performance exceeds the ASHRAE 1999 building code criteria by $50 \%$ on a whole-building level or for a defined portion of the floor space. The tax deduction was set at $\$ 2.25 / \mathrm{ft}^{2}$. The National Electrical Manufacturer's Association (NEMA) and National Resources Defense Council (NRDC) are proposing an amendment that would, in essence, offer "partial deduction" for progress toward the 50\% performance reduction. In addition, the amendment proposed by these organizations would allow for partial deduction by building component (where components here are defined as either lighting, HVAC, or building envelope). The partial deduction for lighting would be implemented on a sliding scale. For all building types but warehouse, the tax deduction would be applied on a sliding scale starting at $\$ 0.375$ for achieving a $25 \%$ reduction in lighting power density below the lighting power density (LPD) requirements of ASHRAE 90.11999/2001 levels (the levels are identical in these two standards), and going to a full \$0.75/sf deduction for buildings achieving a $40 \%$ reduction in lighting power densities. For warehouse buildings, the installed lighting power density must be 50\% below the 90.1-2001 levels to achieve the lighting portion of the tax deduction.

The Joint Committee for Taxation is examining the implications of the proposed amendment. Factors that impact the cost to the Treasury are:

1. The number of building designs that would be stimulated through the provisions of the tax amendment to reduce the LPD level from the level that would have been specified without the amendment to an LPD level at least 25\% lower than 90.1-1999 while also meeting the controls and illuminance requirements required for the tax deduction.

2. The number of building designs that would incorporate LPD level at least $25 \%$ lower than 90.1-1999 while also meeting the controls and illuminance requirements for the tax deduction, without any associated tax stimulus, for the following reasons:

a. Normal lighting design practice without any financial or regulatory stimulus.

b. Lighting designs driven by local building codes requiring lower LPD levels.

c. Lighting designs driven by new energy-efficiency incentives (utility rebates, etc.)

PNNL's analysis is focused on 2.a and 2.b above, for new construction only, excluding building retrofits. Reasons 2.a, 2.b, and 2.c all attempt to identify "free riders" to the tax amendment. For the purpose of this analysis, the volume of free riders can best be enumerated as the square footage of commercial building floor space constructed (or retrofit) that is likely to meet or exceed this $25 \%$ reduction in lighting power level without any tax stimulus. If one wants to estimate the amount of the available tax deduction

\footnotetext{
${ }^{\mathrm{b}}$ Operated for the Department of Energy by Battelle.
} 
that could go to these free riders we also need to estimate the extent to which these free riders exceed the minimum LPD requirements for eligibility.

In this analysis we first generate estimates for the number of free riders and dollar value of the tax deduction available based purely on LPD considerations and then modify these to account for the other control requirements of the tax deduction 


\section{Principal Causes of LPD Free Riders}

Calculating the volume of free riders requires defining a default scenario. In this case, the default scenario is the projection of commercial building lighting without the presence of the proposed tax deduction. In this scenario, three principal categories of free riders can be defined. These are:

1. Floor space currently meeting LPD requirements for deduction without existence of tax deduction amendment or being required by code ("current-practice" free riders)

2. Floor space that would meet LPD requirements for the deduction as a result of complying with new (or revised) building codes that include lighting requirements equal to or above the requirement for the tax deduction ("code-driven" free riders)

3. Floor space that would meet LPD requirements based on other pending tax deduction legislation or incentives (e.g., utility demand side management programs) not yet captured in "current practice".

Of these, this analysis addresses the first two categories of "current-practice" free riders and "codedriven" free riders, where data and information is available to support estimates. No data is available to support effective and uniform analysis of the effects of possible utility programs on a national tax deduction. 


\section{Analysis of Code-Driven LPD Free Riders}

The proposed amendment would provide a tax deduction that would be available through December 31 , 2007, with a 2-year extension for buildings whose designs comply with the provisions of the tax deduction but whose construction is not completed until December 31, 2009. A beginning date was not specified, but for this analysis is assumed to be January 1, 2004. The analysis of the code-driven free riders is primarily concerned with identifying the fraction of construction that would be required by code in each year to have lighting levels lower than those in the 90.1-2001 Standard. Because the lighting design must be certified prior to Dec 31, 2007, these buildings are not influenced by codes that promulgated after that date. We recognize that some fraction of the construction in 2008 will be composed of buildings where the lighting was certified in 2007.

\subsection{Relevant Building Codes}

Building codes are adopted at the State or local jurisdiction, and there are scores of individual building codes used. Each code often provides multiple paths for code compliance. For the purposes of this analysis, State building code levels are lumped into five categories. These are:

- ANSI/ASHRAE/IESNA Standard 90.1-1989 or equivalent energy codes

- ANSI/ASHRAE/IESNA Standard 90.1-1999/2001 or equivalent energy codes

- the draft ANSI/ASHRAE/IESNA Standard 90.1-2004 or equivalent energy codes. This is expected to be published and released in 2004 and will include the new lower LPD values.

- the 2003 International Energy Conservation Code (IECC 2003)

- States without codes or having adopted codes with all lighting levels higher than Standard 90.12001 levels.

Equivalency here means codes that have approximately the same lighting power density requirements for buildings.

ASHRAE 90.1-1989 is historically the basis of most State building energy codes. This is largely the result of the Energy Policy Act of 1992 that requires that States adopt energy codes that provide energy efficiency that meets or exceeds that provided by ASHRAE 90.1-1989.

ASHRAE Standard 90.1-1999 and ASHRAE Standard 90.1-2001 have essentially equivalent lighting power density requirements for commercial buildings. Both of these represent significant lighting power reductions in most (but not all) commercial buildings compared to Standard 90.1-1989 as shown in Figure 1. In one significant category (warehouse buildings), Standard 90.1-1999/2001 levels are significantly higher than the maximum LPDs set in Standard 90.1-1989. 
Comparison of ASHRAE 90.1-1989 LPD requirements with 1999/2001

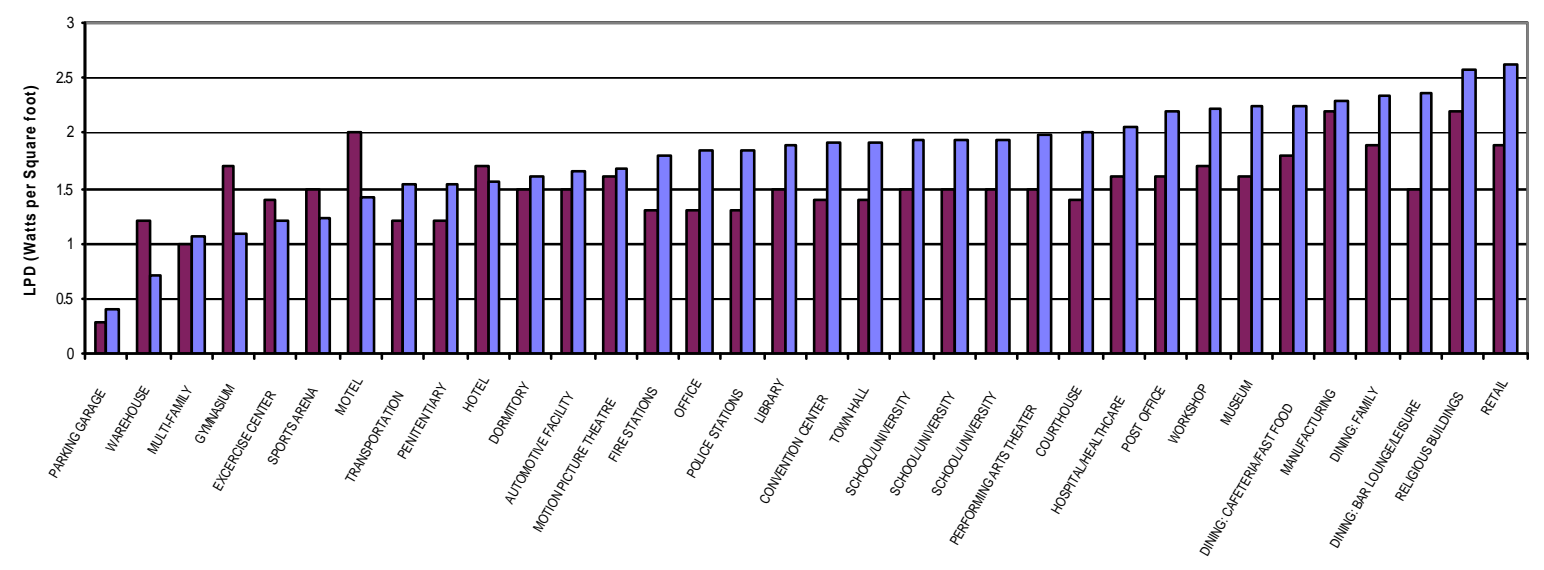

$90.1-1999 / 2001$

प90.1-1989

Figure 1. Comparison of LPD requirements between 90.1-1989 and 90.1-1999/2001.

After Standard 90.1-1999 was published, it was placed on a continuous maintenance process in which addenda to the standard are published as needed, but the entire Standard is only published periodically. Standard 90.1-2001 was the first version of Standard 90.1 to be republished and incorporated mostly minor revisions to Standard 90.1-1999. Subsequent versions are to be published only at three-year intervals. ASHRAE Standard 90.1-2004 will be the next version of the standard published as a whole. Addenda to ASHRAE Standard 90.1-2001 that will be included in the 2004 version are publicly available and can be picked up through the State code adoption process. One of these is addendum $g$ that provides for a reduction of approximately $25 \%$ in average commercial building lighting power densities when weighted by commercial building construction type.

The International Energy Conservation Code (IECC) is a model building energy code developed by the International Code Council (ICC) that is made available for adoption by State and local jurisdictions. The IECC 2003 edition is treated here as a special case because it is the most current version of the IECC available for adoption by States and has been available since early 2003. The IECC 03 contains two significant paths for commercial building code compliance. Chapter 8 of the IECC 03 has minimum whole building lighting power density requirements that were adopted from the ASHRAE development process leading to Addenda $\mathrm{g}$ of Standard 90.1-2001. However, Chapter 7 of the IECC allows commercial buildings to comply Standard 90.1-2001. Because data on the choice of compliance path is not available, for the purposes of this analysis, we treat both IECC 03 paths as equally likely. It is recognized that it would be straightforward for building designers to use the IECC 03's 90.1-2001 reference to determine lighting compliance, which could reduce the number of free riders.

Like ASHRAE 90.1, the IECC publishes yearly amendments, but the full Standard is published only once every 3 years. It is anticipated that the next published version of the IECC will be in 2006 (IECC 2006). At that time, it is expected to reference ASHRAE 90.1-2004 and will likely have consistent lighting requirements between the IECC's 90.1 reference and its Chapter 8 compliance paths. The reference to the lighting in ASHRAE 90.1-2004 will make IECC 06 equivalent to ASHRAE 90.1-2004. 
There are also States without building codes or where the code regulations are significantly less stringent than the other codes described above. States also do not, as a rule, move backwards by rejecting commercial energy codes entirely or adopting codes with significantly less stringent lighting levels.

Finally there are also codes developed by individual States (e.g., California's Title 24) that are largely developed independently of ASHRAE 90.1 or IECC code series. However in most cases, the lighting levels in these codes can be considered to be roughly equivalent to either Standard 90.1-1989 levels or Standard 90.1-1999 levels, and treating them as one or the other category is expected to have minor impact on the free-rider analysis.

\subsection{Estimating the fraction of new construction floor space driven by code to be eligible for a tax deduction}

A five-step methodology is used to determine the fraction of new construction floor space eligible for at least partial tax deduction under the proposed amendment. A variation of the same methodology is used to estimate the value of the tax deduction available to this fraction of new construction. The discussion of methodology is followed by a discussion of the data sources used in the analysis.

\section{Step 1: Determine the national average taxable floor space constructed by building type}

See discussion below for data source.

Step 2: Determine the fraction of taxable floor space qualifying for deduction under each building code.

For each of the five building codes, the LPD for each building type is compared to the LPD requirements in Standard 90.1-2001 for that building type. The taxable floor space weighting for each building type, where the examined code's LPD requirements are sufficient to meet the requirements of the tax deduction, is summed. The result is an estimate of the fraction of new construction floor space eligible for deduction by simply complying with that building code.

Step 3: Determine the fraction of taxable new construction floor space by State See discussion below for data source.

Step 4: Determine the national fraction of taxable new construction floor space under each code for each year of interest.

An estimate is made for each State of the probability that a given code (or code equivalent) will be in use in each year of interest (2003-2007). Then, for each year, the probability of each of the four codes (or code equivalent) being the building code in a State is weighted by the fraction of new construction floor space in that State. The result of this weighting is an estimate of the fraction of national taxable new construction floor space expected under each code for each year of interest.

Step 5: Multiply the fraction of floor space qualifying under each code by the estimate of taxable new construction under that code in each year.

For each year of the study, the fraction of the national commercial floor space in each code is multiplied by total floor area expected to be eligible for at least partial tax deduction under each code as calculated in 
step 2. The result is a national estimate of the fraction of total new construction floor space eligible for at least a partial tax deduction in each year.

\subsection{Estimating the dollar value of tax deductions available to code-driven free riders}

Estimating the dollar value of tax deductions available to the code-driven free riders is similar to estimating the floor space fraction above and is shown in the six step process below.

Step 1a: Determine the national average taxable floor space constructed by building type Identical to step 3, above.

Step 2a: Determine the fraction of tax deduction available to taxable new construction floor under each building code.

For each of the five building codes, the LPD for each building type is compared to the LPD requirements in Standard 90.1-2001 for that building type and the fraction of tax deduction available to individual building types complying with the code is calculated. The fraction of tax deduction available for each building type is then weighted by the taxable floor space weighting factors for each building type to determine the floor-space-weighted fraction of tax deduction available to new building construction, which simply complies with each particular building code.

Step 3a: Determine the fraction of taxable new construction floor space by State Identical to step 3, above.

Step 4a: Determine the national fraction of taxable new construction floor space under each code for each year of interest.

Identical to step 4, above.

Step 5a: Multiply the fraction of deduction available to taxable new building construction under each code from step 2 a by the estimate of taxable new construction under that code in each year (step 4a). For each year of the study, the fraction of the tax deduction available to buildings constructed to just meet each code is multiplied by the national fraction of taxable new construction expected under each code. The result is a national estimate of the fraction of the tax deduction available for taxable floor space that is purely to the result of code compliance.

Step 6a: Convert average fraction of tax deduction available from code compliance to dollar value For each year, multiply the estimate of the fraction of the tax deduction available to taxable floor space from $5 \mathrm{a}$ by the total taxable floor space constructed in that year and by the maximum value of the tax deduction $\left(\$ 0.75 / \mathrm{ft}^{2}\right)$. The result is the estimated dollar cost of the tax deduction to code-driven free riders nationally. 


\subsection{Data Sources}

\subsubsection{Fraction of Construction by Building Type}

Estimates of the fraction of commercial floor space construction by building type are based on 2001 data from F.W. Dodge made available by Owens Corning for use by the ASHRAE 90.1 Standing Standards Project Committee (SSPC). Because the focus of this analysis is on an available tax deduction, the total floor space was subdivided into traditional taxable and non-taxable floor space by building type. Table 1 shows the relative F.W. Dodge new construction floor space data by building type, and the fraction of floor space that was estimated as "taxable" for this analysis. Limited data on what fraction of building construction would be considered "taxable" by building type is available. For school/university, transportation, and office building categories, estimates of "taxable" floor space were based on public/private construction valuation data for those categories (U.S. Census 2003). For other building categories, as simple binary taxable or non-taxable switch was applied based on whether a building would

Table 1. National Commercial Construction Floor Space Weighting by Building Category

\begin{tabular}{|c|c|c|c|}
\hline Dodge Building Category & $\begin{array}{c}\text { National Construction } \\
\text { Weighting }\end{array}$ & $\begin{array}{c}\text { Taxable Fraction } \\
\text { of Floor Space }\end{array}$ & $\begin{array}{l}\text { Weighting of } \\
\text { Taxable New } \\
\text { Construction }\end{array}$ \\
\hline Auto Service & 0.0167 & 1.00 & 0.0206 \\
\hline Exhibition Halls & 0.0083 & 1.00 & 0.0103 \\
\hline Capitols/Court Houses/City Halls & 0.0084 & 0.00 & 0.0000 \\
\hline Food/Beverage Service & 0.0167 & 1.00 & 0.0206 \\
\hline Dormitories & 0.0167 & 0.00 & 0.0000 \\
\hline Gyms/Field Houses & 0.0084 & 1.00 & 0.0104 \\
\hline Police/Fire Stations & 0.0084 & 0.00 & 0.0000 \\
\hline Hospital/Healthcare & 0.0417 & 1.00 & 0.0516 \\
\hline Hotel/Motel & 0.0500 & 1.00 & 0.0618 \\
\hline Libraries & 0.0000 & 0.00 & 0.0000 \\
\hline Theaters & 0.0084 & 1.00 & 0.0104 \\
\hline Museums & 0.0000 & 0.00 & 0.0000 \\
\hline Office & 0.2085 & 0.78 & 0.2011 \\
\hline Parking Garage & 0.1251 & 1.00 & 0.1547 \\
\hline Detention Facilities & 0.0083 & 0.00 & 0.0000 \\
\hline Post Offices & 0.0000 & 0.00 & 0.0000 \\
\hline Religious Buildings & 0.0167 & 0.00 & 0.0000 \\
\hline Retail & 0.1835 & 1.00 & 0.2269 \\
\hline School/University & 0.0917 & 0.18 & 0.0204 \\
\hline Arenas/Coliseums & 0.0083 & 1.00 & 0.0103 \\
\hline Transportation Service/Terminals & 0.0167 & 0.28 & 0.0058 \\
\hline Warehouse & 0.1578 & 1.00 & 0.1951 \\
\hline Total & 1.0000 & 0.8085 & 1.0000 \\
\hline
\end{tabular}

Shaded rows reflect building categories considered "non-taxable" floor space in this analysis. 
be primarily a public space (e.g., courthouse) or not. In addition, all religious buildings were categorized as non-taxable. The total taxable floor space was estimated at $80.9 \%$ of the floor space represented by the Dodge data. Note that this data only addressed "commercial" floor space. Industrial/manufacturing floor space was not represented in the Dodge data and is not addressed in this analysis.

It is recognized that different, more accurate allocation of taxable floor space could be developed on taxable versus non-taxable floor space by building type if more precise data were available.

\subsection{Projection of State Adoption of Codes}

In the course of supporting deployment of Building Energy Codes, DOE's Building Energy Codes Program (BECP) tracks the status of State building energy codes and efforts to improve those codes. Responsibility for tracking State building code status is done by BECP staff supporting the DOE regional offices and the States covered by those regional offices. For this task, those BECP staff were asked to work with the DOE regional offices and other building code contacts to project the likelihood of future code adoption of the four principal building codes (or equivalents) by each State for the period 2004 through 2007. Figure 2 shows the fraction of taxable floor space estimated to be constructed under four different code-equivaknts.

For the purpose of this analysis, code-equivalents are defined by the minimum whole building LPD levels defined for each code in relation to the requirements of the provisions of the tax amendment. Because the amendment requires LPDs at least 25\% below 90.1-2001 levels to be eligible for any tax deduction, States with no building energy codes are treated the same as States with 90.1-1999 or 90.1-2001 based codes.

The analysis projects that light levels equivalent to those in 90.1-2004 will be the codes requirement for $55 \%$ of new taxable construction in 2007. This is based on states who will have adopted 90.1-2004 directly, states adopting the IECC 2003 and using the Chapter 8 path (having 90.1-2004 equivalent lighting levels), states that adopt later versions of the IECC that will likely have both compliance paths equivalent to the 90.1-2004, and states that incorporate similar lighting level requirements into statedeveloped codes (e.g. WA, OR, CA). It should be noted that approximately $22 \%$ of current construction is in states that use 90.1-1999/2001 as the basis of their state code, and another 20\% of constructions is in states that already incorporate many of the 90.1-1999 provisions through various versions of the IECC.

\subsection{Commercial Construction Estimates by State}

Data on annual commercial floor space constructed is not readily available in the public literature. Estimates were developed through a process that involves review of commercial construction valuation data from the U.S. Census, existing building stock data from the DOE/EIA Commercial Building Energy Consumption Survey, State by State building construction cost indices published in MEANS, and commercial building floor space projections used in DOE's National Energy Modeling System (NEMS) tool in preparation of the reference case for the Annual Energy Outlook (AEO) 2002 (DOE/EIA0383(2002)). A detailed discussion of this process is found in Appendix C. 


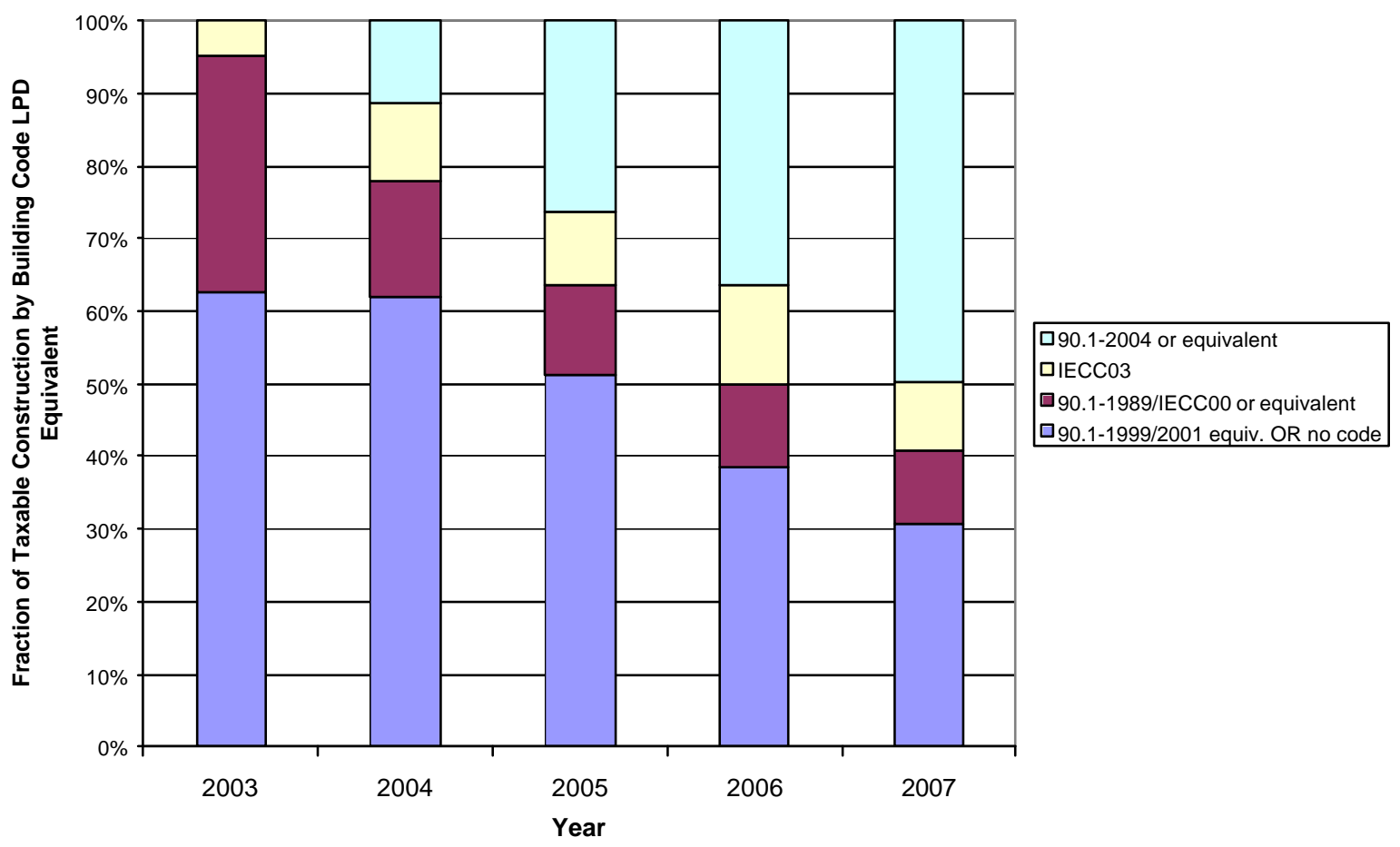

Figure 2. Taxable Floor Space Fraction by Building Code (defined by LPD equivalence).

\subsection{Results of Code-Driven Free-Rider Analysis}

The results of this analysis are heavily dependent on the adoption rate of codes by States, as well as the fraction of code-driven free riders under each particular code. The latter is particularly important in looking at Standard 90.1-2004 based code. Using the national Dodge building weights for taxable floor space, the average LPD reduction between 90.1-2001 and 90.1-2004 is 25.6\%. However, the distribution of LPD reduction by building type is uneven, with a large amount of floor space having reductions near $20 \%$ and a smaller amount of floor space having substantially greater reduction. Figure 3 shows the taxable-floor-space weighted LPD reductions for space eligible for the tax deduction, and not eligible for the tax deduction under Standard 90.1-2004. A 100\% adoption rate of Standard 90.1-2004 would result in about $16.7 \%$ of the building construction floor space with LPDs low enough to qualify for the tax deduction. However, examination of that $16.7 \%$ fraction shows the average LPD reduction to be approximately $36 \%$. Because some building types are below the $40 \%$ threshold needed to get the maximum deduction and some have LPDs which exceed that required for the maximum deduction, the fraction of tax deduction available when averaged over all building floor space was $13.8 \%$ under 90.12004. 


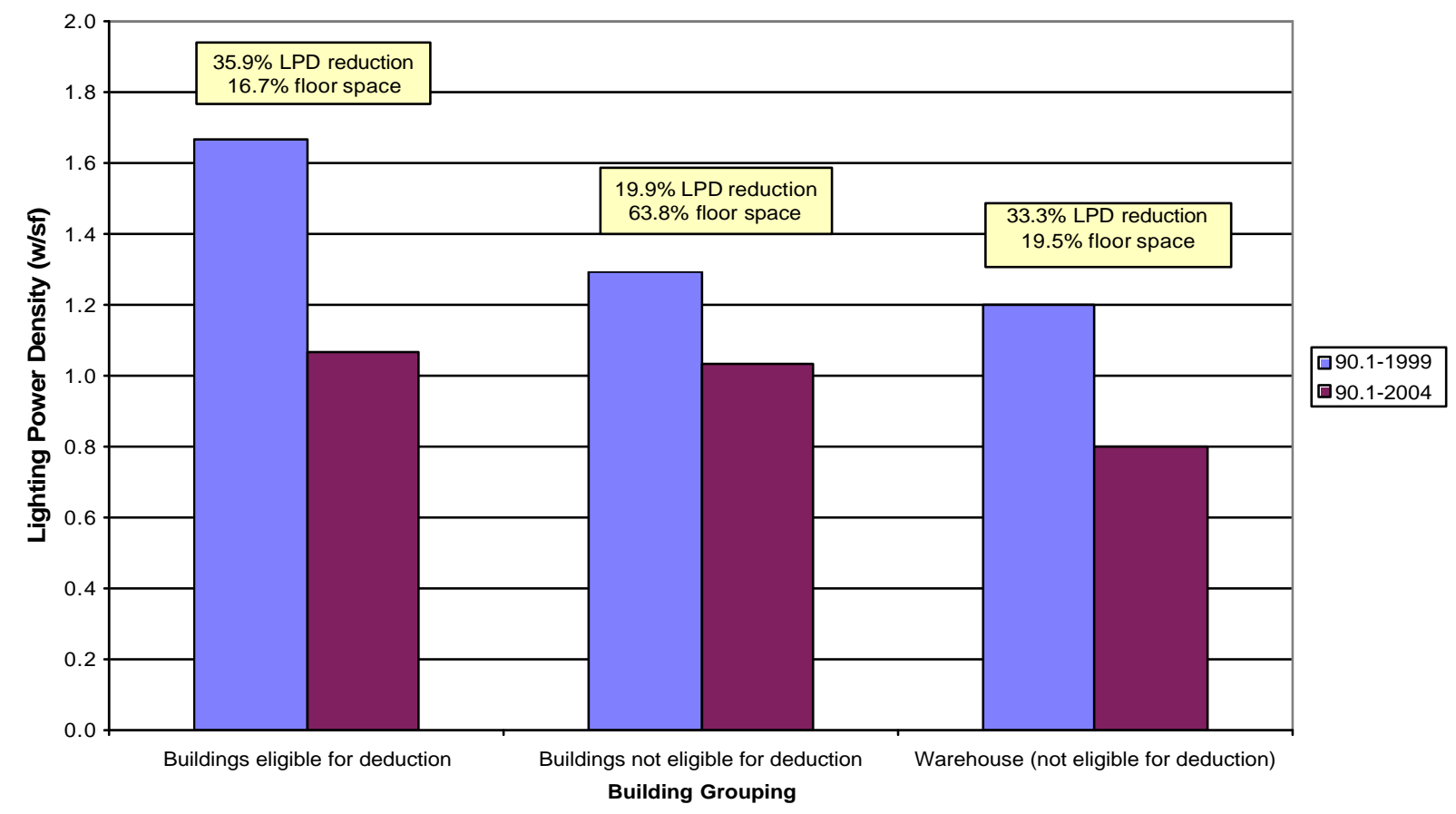

Figure 3. Average LPD Change for 90.1-2001 vs 90.1-2004 for Taxable Floor Space.

Under Standard 90.1-1989, only an estimated 3.6\% of the taxable floor space was estimated to qualify for a tax deduction, with the weighted average tax deduction available to all floor space being $2.7 \%$. It is important to point out that these results were obtained using a consistent, approach to lighting compliance under both 90.1-1989 and 90.1-2001. This is based on using the same space-by-space approach applied to a default set of buildings of each building type for both codes. 90.1-1989 also provides a separate whole building approach to lighting compliance that provides different LPD requirements, but only for a limited subset of building types. For two building types in particular (warehouse buildings and parking garages), the taxable floor space with LPDs eligible for the tax deduction increases substantially when using the whole building LPD approach under 90.1-1989. This increases the percentage of total building stock eligible (based purely on LPD considerations) to approximately 33.2\% under 90.1-1989. However, in much of this floor space, PNNL review suggests that strict compliance with these low 90.1-1989 light levels would result in buildings unable to meet the $9^{\text {th }}$ edition IESNA light levels required for the tax deduction. There is also a declining fraction of buildings using 90.1-1989 based codes over the period the tax deduction is available (see figure 2). Due to lack of data on use of different compliance paths, we have taken a conservative approach to the number of code-driven free riders and have not addressed this issue further in the analysis.

Under the IECC 03, the assumption of 50\% of stock complying via the Chapter 8 approach results in an average of $8.3 \%$ of floor space qualifying for a tax deduction, and the average fraction of tax deduction available was $6.9 \%$. 
Figure 4 shows the results of taking into account each of the three principle codes and the expected rate of code adoption. Floor space available for at least a partial tax deduction solely as a result of code compliance climbs from 3.4\% to 9.5\% over the period from 2004 through 2007.

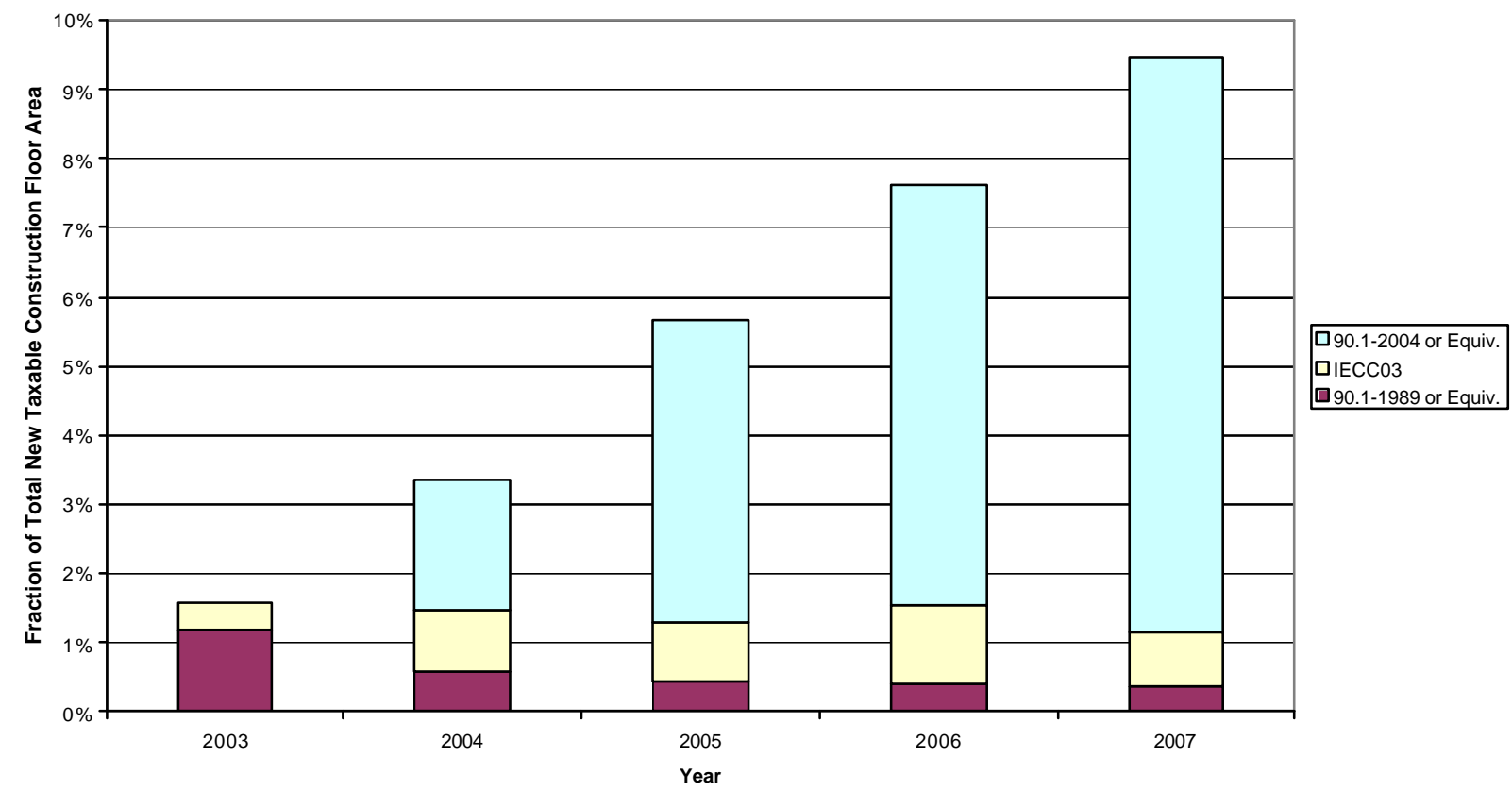

Figure 4. Fraction of Taxable New Construction Floor Space Eligible for Tax Deduction by Year through Code Compliance (assumes $100 \%$ code compliance).

Current building construction estimates suggest that approximately 1.95 billion square feet of floor space a year is constructed in the U.S. As noted previously, it was estimated that approximately $81 \%$ of this floor space could be considered as taxable. By developing the fractional tax deduction discussed above and multiplying it by the estimated national new construction volume, we estimate the total tax deduction that could be provided to "code-driven" free riders. The results over the time period 2004 through 2007 are shown in Figure 5. The "value" of the tax deduction resulting solely from buildings complying with building codes is estimated to grow from 32.4 million dollars per year to 92.0 million dollars per year over this time frame.

The current language for the tax-amendment would also allow it to apply for building renovation. The amount of renovated floor space could be as much as $30 \%$ of new construction annually, and some fraction of this might be acceptable for some type of tax deduction under this amendment. Building codes in theory apply to many renovations and retrofits, but in practice may not be followed in many renovations where code inspection is not enforced. In addition, lighting may not be a part of all renovations. For the purposes of this analysis, renovations have not been counted. Tax deductions for renovations to code would tend to increase the total floor space and monetary value associated with free riders. 


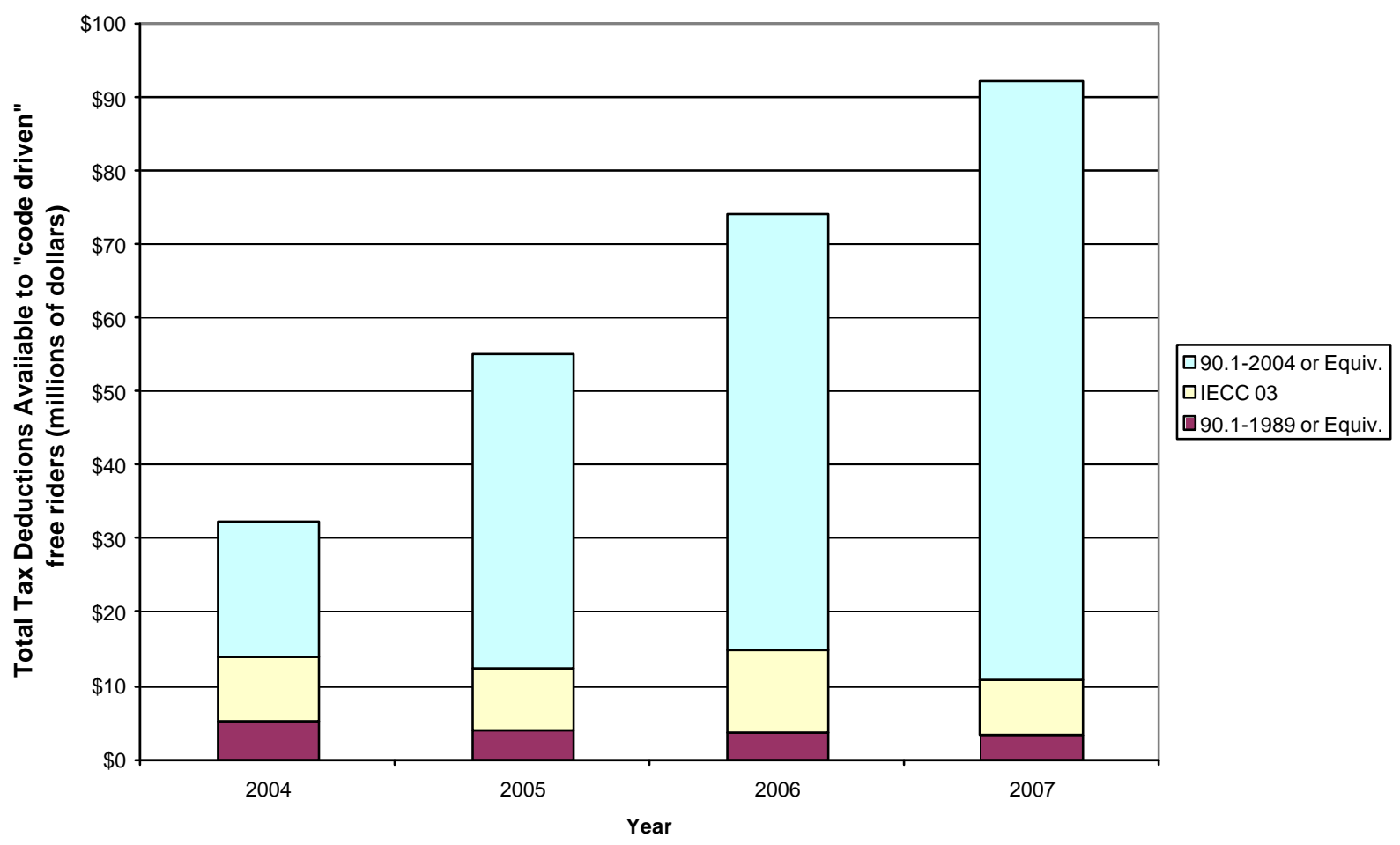

Figure 5. Value of Tax Deduction Available to Free Riders from Building Codes (new construction only). 


\subsection{Current Lighting Practice Free Riders}

The lighting power density (LPD) of specific buildings can vary greatly from others of a similar type. This can be driven by many factors other than code requirements including economics, environment, corporate desires, building structure, and current design practice. A portion of these varying LPDs will fall below the threshold for tax deduction (partial or full). This analysis identifies and evaluates the effect on free riders of this natural variation in LPD in new construction.

It is useful to understand the factors involved in lighting design as currently practiced and how they can affect free riders.

1) Economics - The cost of energy and lighting equipment generally leads to more energy efficient, and therefore less costly, lighting designs. However, as with most energy related design decisions, this is often not an automatic effect but rather requires a champion within the design team. This can occur naturally through a progressive design firm but is likely more often driven by other factors such as corporate wishes or codes.

2) Corporate desires - Many large and small corporations and building owners have specific desires and/or requirements for lighting design. One example is the noted desire by many retailers to provide as much light as possible because the belief is that this will have a direct effect on sales. These become another set of design inputs that cause variations in LPDs among similar buildings and lead to increased LPD values in some cases. In other cases, progressive corporations may be very interested in "green" designs and very low building energy use including lighting, resulting in lower LPDs

3) Environment - as "green" buildings becomes more of a mainstream idea, energy efficiency tends to follow. This effect can be driven by progressive architectural design firms, corporate desire, or marketing interest, and can be bolstered by available rating systems such as the LEED rating system.

4) Structures vary across buildings and create a wide variety of internal space arrangements even for single-use building types such as offices. This will naturally cause differences in whole-building LPDs because designers light spaces to their individual needs. This creates a potential problem when comparing these "real world" values with code requirements or tax deduction thresholds that necessarily must break the world of buildings into discreet groups with similar characteristics and therefore LPDs.

5) Current practice incorporates several factors in lighting design. These include industry standard recommendations or practices. The most notable of these is the set of illuminance recommendations from the Illumination Engineering Society of North America (IESNA). When these recommendations change, an eventual change in designs may be seen. A recent major update of the IESNA illuminance recommendations occurred in the 1999-2000 time frame (IESNA Handbook, Ninth Edition). However, because these are generally voluntary recommendations, there is likely no immediate effect on practice. Sales information for the handbook that include these illuminance recommendations was provided by the IESNA ${ }^{\mathrm{c}}$. The information provided showed that approximately two thirds of the purchases of the new handbook edition were not to past handbook purchasers. This supports the idea that the mere

\footnotetext{
${ }^{c}$ Personal phone conversation with Rita Harrold, IESNA, September 2, 2003
} 
existence of new, recommended illumination levels does not automatically mean that they are immediately adopted or applied by the lighting design community. Other factors influencing design choices include the introduction of new equipment choices and light source technologies (color, efficiencies, etc.).

\subsection{Analysis of Current-Practice Free Riders}

Current design practice can result in improved building effic iency in the absence of tax incentives or code requirements. As described previously, there are many potential reasons for energy efficient building design. To analyze these effects, an understanding of current and future design is desirable. While it is not possible to estimate future lighting design with any certainty, it is possible to examine current practice.

Current-practice construction data is not readily available in data sets of the size desired to analyze national impacts such as that caused by tax credit legislation. This analysis makes use of a national data set $\left(\mathbf{N C}^{3}\right)$ that has the correct type of data but is still limited in sample size. Other data sets exist but are either lacking in appropriate detail or are based on limited geographic scope.

\subsubsection{National Commercial Construction Characteristics Database $\left(\mathrm{NC}^{3}\right)$ Data Source}

The National Commercial Construction Characteristics Database $\left(\mathrm{NC}^{3}\right)$ developed under the BECP program at PNNL provides a limited data set of national current-practice information. This data set is currently populated with energy related construction details from 162 newly designed commercial buildings randomly selected from across the US. Data include over 130 different building characteristics collected from sets of plans and specifications that were in the bid process in 2001 and are, therefore, at most 1 year old. These data were collected from actual sets of plans purchased from the F.W. Dodge Construction plans database. Data collection was designed to ensure completeness. Extensive quality and completeness checks were performed on each set of building data to ensure consistency and accuracy. Not all sets of plans received from the F.W. Dodge set represented complete constructions details and, therefore, details in all construction areas are not necessarily available for all buildings. For example, some of the building plans note building areas where the lighting is to be specified by a future tenant and therefore it is not available on the plans. In other cases, the electrical contract was not part of the bid and no lighting details were available. For those buildings where complete electrical and lighting data were available, the data set does provide very detailed lighting information.

In general, the data set provides exact fixture and lamp counts and ballast types for each space type in the building. This allows calculation of LPDs from the data set for space types and whole buildings with relatively good accuracy.

For this analysis the data for each of the buildings in the data set was reviewed to ensure it was a complete and accurate representation of all lighting and matching floor area so that an accurate LPD could be calculated for each building. For each building type, the buildings in the data set with low enough LPDs were compared against the appropriate tax deduction threshold and a potential free-riders percentage established. This percentage was then multiplied by the construction weights for each building type from Table 1, and divided by the total weight of all building types represented in the $\mathrm{NC}^{3}$ 
data set. The sum of the results of this across all $\mathrm{NC}^{3}$ building types is representative of the total U.S. taxable new construction building square footage that may be a tax deduction free rider.

Advantages of the $\mathrm{NC}^{3}$ data set for this analysis include:

- Verified new construction status

- Personal knowledge of data collection and completeness

- Nationally representative data based on a random sampling of new construction across the US

Potential disadvantages include:

- Current status of buildings (whether the buildings are built or not) is not known. The $\mathrm{NC}^{3}$ data set is based on design plans and does not include any potential as-built conditions. No data are available to determine this effect.

- Relatively small sample size to represent national trends. Samples range from 10 to 30 buildings of each major type.

It is important to have an understanding of the weaknesses of this kind of data and how these can affect the resulting estimate of free riders. For this type of analysis, the data presents relatively small samples for specific building types. Therefore, when a few of these buildings are identified as having an LPD that might receive a deduction, it is not known how well these few buildings represent an average across the country. The analysis of free riders relies on a simple fraction of buildings in the sample that have low enough LPDs to apply for a deduction. If the these potential free-rider buildings are an unknown subset of the basic building type, then considering them to be representative of similar building type U.S. square footage would be a potential source of error. This error could be very significant given the sample sizes. For example, the one offic e building in the $\mathrm{NC}^{3}$ data set that is a potential free rider is a very small building that is primarily one large general meeting room with a small amount of office and support space around it. It is not expected that this is a true representation of all potential office free riders, because it cannot be assumed that office free riders will all be small buildings. Therefore, extrapolating the percentage of total U.S. office building free riders based on this buildings ability to apply for a tax deduction could represent a higher than expected free-rider availability.

\subsubsection{Other Data Sources}

Other building construction data sources considered for use in this analysis include Ecotope (Kennedy and Baylor 2001) and RLW Analytics (RLW Analytics 2000) non-residential buildings survey studies. The Ecotope study explored relatively new commercial construction (1995-2000) in the Seattle, Washington area. The RLW Analytics study was restricted to recent construction (1995-1999) in California. These data sets had sample sizes for building types similar to the $\mathrm{NC}^{3}$ data set. However, their use was limited for this analysis for the following reasons:

- Both are West Coast samples and do not represent a cross section of national construction. 
- Both sets of samples are from generally progressive energy States with their own unique codes making them less representative of a national cross section that generally adopts the ASHRAE or IECC energy codes and standards.

- The detailed collection data for each building in the sample is unknown. While their descriptions of the methodologies indicate these data are likely as complete as possible, without specific review of the raw data there is naturally less confidence in the data's completeness.

A more detailed examination of these other data sets compared with the NC3 data is found in Appendix D. Comparison of this data is provided by building type, but overall indicates that the NC3 data does not represent an extreme in terms of LPD free ridership.

\subsection{Results of Current-Practice Free-Rider Analysis}

Table 2 shows the building types represented in the $\mathrm{NC}^{3}$ data set. Column 2 in the table shows the fraction of buildings that would be eligible for a tax deduction. Column three shows the average reduction in lighting below Standard 90.1-2001 levels within this data set.

Table 2. Fraction of Buildings Eligible for Tax Deduction by $\mathrm{NC}^{3}$ Data Set

\begin{tabular}{|c|c|c|c|}
\hline 90.1-1999 Bldg Type & $\begin{array}{l}\text { Percent of buildings } \\
\text { that meet LPD } \\
\text { requirement for a full or } \\
\text { partial tax deduction }\end{array}$ & $\begin{array}{l}\text { Average \% LPD below } \\
\text { ASHRAE 90.1-2001 } \\
\text { levels for eligible } \\
\text { buildings }\end{array}$ & $\begin{array}{l}\text { Sample } \\
\text { size }\end{array}$ \\
\hline COURTHOUSE & $0.0 \%$ & $0.0 \%$ & \\
\hline DORMITORY & $0.0 \%$ & $0.0 \%$ & \\
\hline GYMNASIUM & $0.0 \%$ & $0.0 \%$ & 2 \\
\hline HOTEL/MOTEL & $33.3 \%$ & $48.5 \%$ & 6 \\
\hline OFFICE & $4.8 \%$ & $44.7 \%$ & 21 \\
\hline RELIGIOUS BUILDINGS & 0.75 & $43.8 \%$ & 4 \\
\hline RETAIL & $26.1 \%$ & $41.4 \%$ & 23 \\
\hline SCHOOL/UNIVERSITY & $37.5 \%$ & $32.6 \%$ & 8 \\
\hline TOWN HALL & $0.0 \%$ & $0.0 \%$ & \\
\hline WAREHOUSE & $28.6 \%$ & $64.6 \%$ & 7 \\
\hline DINING: BAR LOUNGE/LEISURE & NA & $0.0 \%$ & \\
\hline DINING: CAFETERIA/FAST FOOD & NA & $0.0 \%$ & \\
\hline DINING: FAMILY & NA & $0.0 \%$ & \\
\hline HOSPITAL/HEALTHCARE & NA & $0.0 \%$ & \\
\hline MANUFACTURING & NA & $0.0 \%$ & \\
\hline PARKING GARAGE & NA & $0.0 \%$ & \\
\hline WORKSHOP & NA & $0.0 \%$ & \\
\hline $\begin{array}{c}\text { Fraction of taxable floor space } \\
\text { represented by sample }\end{array}$ & $74 \%$ & & \\
\hline
\end{tabular}

Building types shown in gray not in $\mathrm{NC}^{3}$ data set. Religious buildings excluded from analysis because of general tax exempt status. 
By applying the appropriate F.W. Dodge taxable construction weights to the percentages in column 2 of Table 2 and normalizing for the percentage of taxable floor space represented by the $\mathrm{NC}^{3}$ buildings, it is possible to estimate the floor space in the national population that are potential current-practice free riders. These estimates are shown in Figure 6 broken out by building type using the $\mathrm{NC}^{3}$ data set. .

New Construction Floor Space Eligible for Tax Credit

Current Practice (NC3 Data Set)

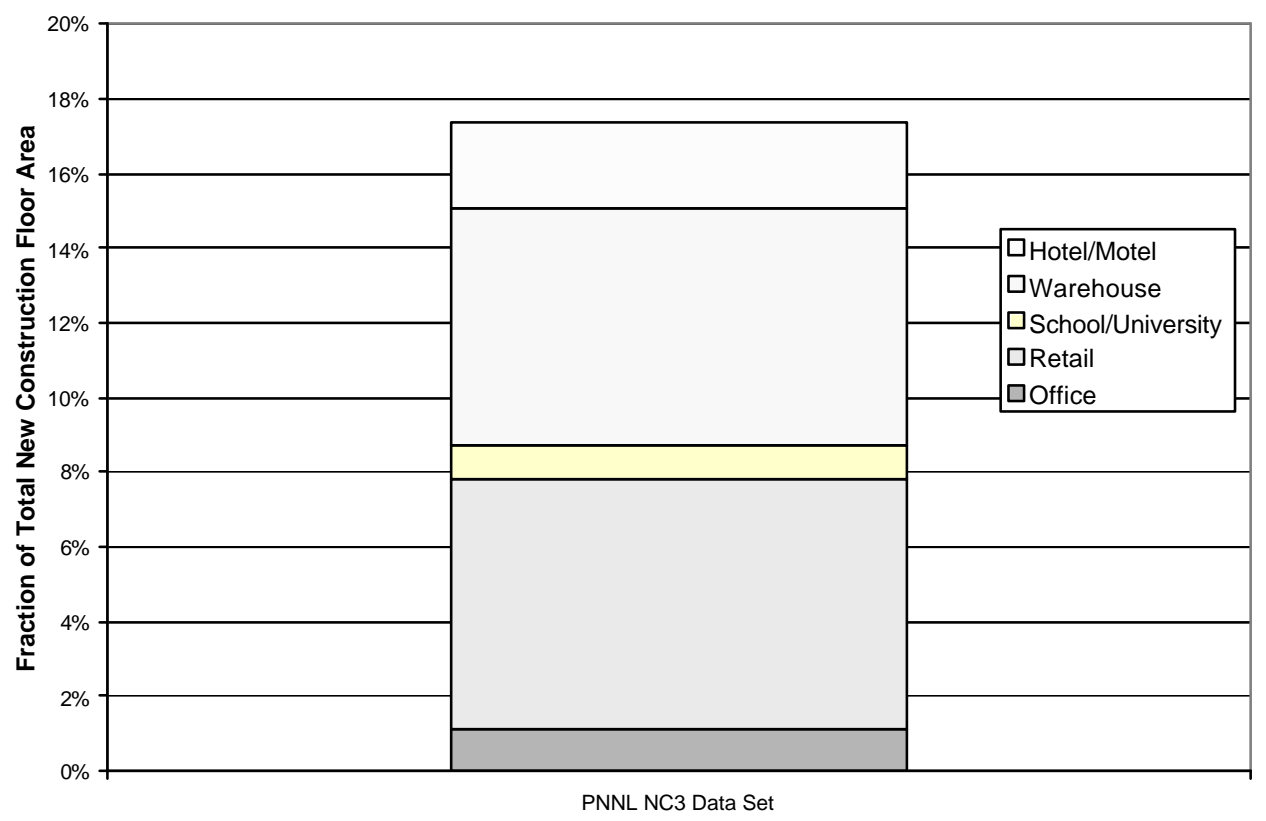

Figure 6. New Construction Floor Space Eligible for Tax Deduction ( $\mathrm{NC}^{3}$ data set).

Similarly, applying the same national construction weights to the available tax deduction percentages based on column 3 in Table 2, and multiplying by the total taxable floor space constructed annually (1.57 billion sf) and the appropriate lighting portion tax deduction of $\$ 0.75$ per square foot produces an annual tax deduction available to current-practice free riders of 204 million dollars annually.

The data from the $\mathrm{NC}^{3}$ data set for the taxable building types suggested that there are potentially a significant fraction of free riders $(17.4 \%)$ and that, when the taxable floor space weights are taken into account, most of the current-practice free riders identified were eligible for all of the $\$ 0.75 / \mathrm{ft}^{2}$ tax deduction.

The remaining tax deduction requirements also have potential current-practice components that must also be addressed.

Compliance with the controls and circuiting requirements of Standard 90.1-2001 could occur as part of current practice. Data to support an estimate of this is unavailable at a national level. Data from the $\mathrm{NC}^{3}$ database for a sample of 33 office buildings across the U.S. indicates that in no case were occupancy sensors used regularly for either individual office space or for most public spaces (e.g., store rooms, conference rooms, copy centers). Occupancy sensors are one option for complying with the automatic 
lighting control requirements in 90.1-2001. Data on the use of other options for compliance, such as whole building lighting controllers, was not available.

Compliance with the bi-level switching requirement can also effect the number of free riders because this will be an additional cost to claim the deduction if it is not already part of current practice. The NC3 data provided information on bi-level switching for 33 office buildings across the nation. The results showed that approximately $23 \%$ of these offices made substantial use of bi-level switching. If this fraction can be considered representative of bi-level switching in other building types, then a $23 \%$ factor could be used to modify the potential LPD level free riders and represent the free riders that may not need to make any changes in building design to qualify for the deduction. 


\subsection{Combining LPD Code Driven and Current-Practice Free Riders}

No attempt has been made to rigorously estimate the number of free riders from the combination of both code-driven free riders and current-practice free riders. However, given the nature of the building codes, it is expected that adoption and enforcement of new building codes in the 2004-2007 time frame will have little direct impact on the fraction of the building population who are likely to design lighting power density levels from $25 \%$ to $60 \%$ below the recommendations of ASHRAE 90.1-2001 on ther own. Hence, if that $17.4 \%$ of the floor space nationally is unaffected by the adoption of building codes, new code compliance free riders must be reduced by the same $17.4 \%$. New code enforcement would then be expected to result in approximately $2.8 \%$ (82.6\% of $3.4 \%$ ) in 2004 , rising to $7.8 \%$ (82.6\% of $9.5 \%$ ) of the building construction being code-driven free riders in 2007. Total free riders would rise from approximately $20.2 \%$ of the floor space constructed in 2004 to $25.2 \%$ of the floor space constructed in 2007. The "cost" of the total (code plus current practice) free ridership in terms of potential tax deductions is on the order of 230 million dollars in 2004 to a peak of 280 million dollars per year in 2007. This estimate does not include the additional tax deductions that might be available to free riders in building retrofits. 


\subsection{Impact of Other Requirements for the Tax Deduction}

Other factors affecting the ability to meet the requirements for the tax deduction include complying with the lighting control requirements of the ASHRAE 90.1-2001 Standard, installing bilevel switching, and meeting the current minimum IESNA illuminance recommendations. These factors can be represented by the following two mathematical representations of the major paths to free riders. The first free-rider path is based on current typical lighting design practice:

Current-practice Free-rider square footage = LPD-CP x ContComp x BiLevComp x IllumComp

where:

LPD-CP = the effective square footage across the Nation that could be eligible for the tax deduction at full deduction value based solely on current LPD practice

ContComp = expected compliance with 90.1-2001 control requirements for lighting systems

BiLevComp $\quad=$ expected compliance with the bilevel switching requirement

IllumComp $=$ expected compliance with the recommended illuminance requirements.

The data available from $\mathrm{NC}^{3}$ data set to estimate the percentage of commercial floor area under construction across the Nation that currently incorporates lighting power densities at a level that meets the LPD tax deduction requirement suggested an estimated effective current-practice free-rider square footage percentage of $17.4 \%$ from LPD levels (LPD-CP) alone. This value is considered an upper bound for the current-practice free riders because it does not include effects of other factors that are also required for complete compliance with tax deduction code requirements.

There is some data available from the $\mathrm{NC}^{3}$ data set to estimate current-practice use of bi-level switching (BiLevComp). The data indicates that potentially $23 \%$ of current construction does include bi level switching (based solely on office building usage). There was no available data or information to indicate that compliance with the illuminance light level requirements (IllumComp) would not be achieved nor is it clear how documentation of this requirement would be achieved. Applying only a BiLevComp factor of $23 \%$ would revise the estimate of the percentage of current-practice free-rider square footage downwards to $4.0 \%$. Those building owners who are only required to add bi-level switching in order to meet the requirements of the tax deduction may be able to do so with less effort and incremental cost than those who would be required to do a complete lighting redesign to reduce installed lighting power levels in addition to incorporating bi-level switching Building owners may choose to incorporate these bi-level controls knowing that they may be completely (or partially) offset by the value of the deduction and this could impact the percentage of free riders The percentage of free riders could further be modified by the remaining factors of compliance with lighting controls (ContComp) and illuminance levels (IllumComp) if data was available for these factors.

The second free-rider path to consider is based on expected code adoptions. The equation for free riders under than path is similar:

Code Adoption Free-rider square footage $=$ LPD-CA x STNDComp x BiLevComp x IllumComp $\mathrm{x}$ kadj 
where:

LPD-CA = the effective square footage across the Nation that could be eligible for the tax deduction at full deduction value based solely on code adoption LPD levels. This factor incorporates the varying expected code adoption dates for the major national energy codes.

STNDComp = expected compliance with 90.1-2001 lighting requirements. This Factor accounts for the fact that compliance with standards is less than $100 \%$.

BiLevComp $=$ expected compliance with the bilevel switching requirement

IllumComp $=$ expected compliance with the recommended illuminance requirements.

$\mathrm{k}_{\mathrm{adj}}=$ (total construction square footage - current practice free-rider square footage) / total construction square footage. This adjustment factor accounts for the current-practice free riders who are already exceed any code-driven requirements.

As discussed above, the estimate for the net code-driven free-rider floor space is approximately $2.8 \%$ of taxable construction in 2004 growing to $7.8 \%$ in 2007 (after accounting for current-practice free riders not affected by codes). Adjusting for less than $100 \%$ code adoption and enforcement would likely reduce the number of code-driven free riders further.

As discussed previously, no data is available to assess the effects of the (IllumComp) factor. However, building codes are very clear on the STNDComp and BiLevComp factors. Compliance with the 90.12001 controls (the STNDComp factor) is required by 90.1-2004 as well as the IECC, and would be a code requirement for roughly $22 \%$ of the taxable building construction in 2004, rising to $59 \%$ in 2007 based on the scenarios for State code adoption.

A requirement for bi-level switching only exists in one of the compliance paths in one of the code options examined (IECC 2003). The IECC 2003 is estimated to be the required code for approximately $11 \%$ of the taxable building construction from 2004 through 2007. Assuming 50\% of construction under the IECC 03 uses the chapter 8 compliance path would result in $8.3 \%$ (50\% of 16.7\%) of taxable floor space under the IECC 03 having 90.1-2004 equivalent lighting levels, 90.1-2001 equivalent occupant lighting controls, and bi-level switching requirements. The product of the floor space constructed under the IECC 03 and the estimated $8.3 \%$ fraction of floor space under that code path that qualifies for a tax deduction results in the fraction of free riders who purely by code would be expected to meet both the LPD and the bi-level switching and other control requirements closer to $1 \%$.

A more accurate assessment may come from noting that the $\mathrm{NC}^{3}$ data set showed that extensive use of bilevel switching was incorporated in approximately one-fourth of office buildings without being required to by code. If that fraction continues to hold true as new building codes with lower LPD levels and with the 90.1-2001 lighting control requirements are adopted, the fraction of free riders who meet all LPD and control requirements might be approximately one-fourth of those who just meet the code-driven LPD requirements, or $1.8 \%$ of taxable floor space. As with the current-practice free riders discussed above, for those buildings that meet the LPD and basic lighting control requirements because of code, the 
incorporatation of bi-level switching would qualify them for the tax deduction and its costs could be wholly or partially offset by the value of the tax deduction to the building owner. 


\subsection{Conclusions}

The analysis of both the "current-practice" free riders and the code-driven free riders indicated that the total number of free riders is potentially as high as $25.2 \%$ by 2007 , a factor of about 2.5 times the maximum number of free riders expected during the period from the adoption of near-term building codes, when only the LPD requirements of the deduction are examined. The impact of the total (code plus current-practice) free riders in terms of potential tax deductions available to free riders will grow from \$231 to \$280 million dollars per year for the period 2004 through 2007 based solely on new construction meeting the lighting power density $(L P D)$ requirements of the proposed tax deduction but not considering the effects of control requirements. This reflects $20.2 \%$ to $25.2 \%$ of the new construction floor space meeting these LPD requirements and does not address building renovations that might also apply for the tax deduction.

The degree to which other conditions required by the tax amendment are incorporated will significantly reduce the expected free riders. Accounting for lighting controls and bi-level switching requirements also required for compliance with the provisions of the proposed amendment would likely reduce the estimated value of the tax deductions available to free riders down to approximately $\$ 59$ million dollars per year on average from 2004 through 2007 or approximately $6 \%$ of new taxable floor space. This second, lower estimate represents free riders that would likely not be required to do anything to achieve the deduction. The higher value discussed previously includes those free riders that may already have achieved the LPD requirements for the tax deduction and much of the associated energy savings (from the reduction in lighting power density) but would need to make some additional controls changes to be eligible for the deduction. It is recognized that for buildings that comply with the LPD requirements for the tax deduction, the addition of these other controls may make them eligible to receive the tax deduction with little additional cost and unknown energy benefit.

A number of caveats exist to this analysis, which, if more data were available, could result in a raising or lowering of the estimated fraction of free riders. These caveats include assumptions about code adoption and compliance, the lack of specific treatment of all local and State developed codes individually, the likelihood of different compliance paths being used, exclusion of renovations floor space, and most importantly the limited amount of data on current construction practice that could be used to assess the current-practice free riders. This analysis focuses on the LPDs needed to apply for the tax deduction, but provide a preliminary assessment of the impact that the further control requirements might have on reducing the number of free riders. It does not address the requirement that lighting would need to provide light levels that meet the minimum requirements set forth in the $9^{\text {th }}$ edition of the IESNA Lighting Handbook (IESNA 2000). Finally, the analysis did not estimate the fraction of those eligible for the tax deduction that would actually apply and receive the deduction. As such, the LPD only portion of our estimates should be viewed as upper limits on both floor space affected and impact on tax revenues. Development of a more accurate estimate of the cost to the Treasury of free riders and "near" free riders would likely require a significantly more detailed economic study of the cost of meeting and documenting the lighting control requirements in view of the potential tax benefit to the building owner. 


\subsection{References}

ANSI/ASHRAE/IESNA. 2001. "Energy Standard for Buildings Except Low-Rise Residential Buildings." Standard 90.1-2001, American Society of Heating and Refrigeration Engineers, Atlanta, GA.

ANSI/ASHRAE/IESNA. 1999. "Energy Standard for Buildings Except Low-Rise Residential Buildings." Standard 90.1-1999, American Society of Heating and Refrigeration Engineers, Atlanta, GA.

ANSI/ASHRAE/IESNA. 1989. "Energy Standard for Buildings Except Low-Rise Residential Buildings." Standard 90.1-1989, American Society of Heating and Refrigeration Engineers, Atlanta, GA.

IECC 2003 “International Energy Conservation Code.”, International Code Council, Falls Church, VA.

IESNA. 2000. “The IESNA Lighting Handbook Reference \& Application.” Ninth Edition, Illuminating Engineering Society of North America, New York.

F.W. Dodge. 2001. Dodge construction floor plans downloaded via the internet in Summer 2001, "http:/dodge.construction.com/plans"

M. Kennedy and D. Baylon. 2006. "Survey of Energy Efficiency in Seattle's New Non-Residential Buildings: 1995-2000.” Ecotope Consulting, Seattle, WA.

RLW Analytics. 2000. "Updated Baseline Compared to 1998 T-24 Code \& End Use Savings by Measure Category: A Follow-on to the Nonresidential New Construction Baseline Study

Project.", RLW Analytics, Inc., Sonoma, CA

Washington State Building Code Council. 1997. “ 1997 Washington State Energy Code (WSEC).”, Washington State Building Code Council, Olympia, WA.

MEANS 2002, "RS MEANS Square Foot Costs, $23^{\text {rd }}$ Annual Addition", RS MEANS COMPANY, Inc, Kingston MA

DOE/EIA-0383(2002), 2001, "Annual Energy Outlook, 2002". U.S. Department of Energy, Washington D.C.

Energy Information Administration (EIA). 1992. "1992 Commercial Building Energy Consumption and Expenditures (CBECS)", Public Use Data, Micro-data files on EIA website:

ftp://ftp.eia.doe.gov/pub/consumption/commercial/micro.data/

Energy Information Administration (EIA). 1995. "1995 Commercial Building Energy Consumption and Expenditures (CBECS)", Public Use Data, Micro-data files on EIA website:

http://www.eia.doe.gov/emeu/cbecs/microdat.html

U.S. Census. 2002. "C30 Value of Construction Put in Place.”, reports accessed via the internet at: http://www.census.gov/const/C30/TOTSA2002.pdf 
Appendix A

\section{National Energy Standard LPD Development}




\section{Appendix A National Energy Standard LPD Development}

The development of the 90.1-1999, 2001, and 2004 lighting power density values all follow the same basic methodology. The methodology focused on deriving appropriate individual space type and whole building lighting energy limits that promote lighting energy effic iency without sacrificing good design and quality lighting. To accomplish this, a methodology was developed that makes use of currently available lighting product characteristics, light loss factors, building construction data, and professional design experience. The central calculation portion of the methodology is the use of application (design) models that define typical quality design and use a modified form of the lumen method to calculate individual space type LPDs. These models and their power densities are then applied to new construction building space data to form similar whole building values.

\section{Individual Space Type LPD Development}

The inputs to the individual space type models involve four basic elements in determining appropriate lighting density requirements without sacrificing good design and quality lighting.

The first element is the use of representative manufacturer's reported characteristics and performance data for currently available energy-efficient lighting products and current new building construction data. Manufacturer's data is used to determine typical coefficient of utilization (CU) values for each representative fixture type that is commonly used in current lighting design. New building construction data ( $\mathrm{NC}^{3}$ database) is used in applying the power densities determined for individual spaces to create power densities for whole buildings. The second element is the use of typical light loss factors and lamp efficacies for efficient sources in each lamp type category. These first two elements combine to form the technical database, which is where the foundation of energy efficiency begins- choosing the most efficient and cost effective technologies given current equipment availability.

A third element is the use of IESNA recommended light level data presented in the Lighting Handbook. These values provide the basis for ensuring that the standard does not promote energy efficiency at the expense of internationally accepted lighting levels.

The fourth element is the application of professional lighting design consensus. This design consensus allows the lighting power density numbers to be based on real design experience, and applies energy efficient equipment in achieving lighting quality and occupant comfort.

The use of these four elements allows for the development of lighting density numbers that incorporate current efficient lighting luminaire characteristics, accepted lighting technology efficiency and loss factors, IES illuminance recommendations, and practicing lighting designer experience and consensus. This method provides technical background and documentable calculations of consistent values, which have not existed in any other national codes to date.

The four elements are combined in a comprehensive spreadsheet format that calculates individual space type LPD values that are achievable and eliminates poor design and inefficiency. This set of values provides the requirements to show compliance with the standard by characterizing the lighting power use in each building space. The alternate method, and the one easiest and most likely to be used, is an 
accounting of lighting power at the whole building level. This requires the calculation of appropriate whole building LPDs.

\section{Whole Building LPD Development}

Whole building LPD values found in national energy standards have typically come from regional data (e.g., California, New York) or single building lighting analysis results (ASHRAE special project 41). This process left the determination of widely used whole building LPDs without any rigorous basis. The process used for the 90.1-1999 values incorporates detailed real building space type data for a large number of buildings. Building space type percentages for each building type are derived entirely from multiple sets of newly constructed or contracted building plans from the extensive collection of full building drawing sets owned and maintained by F.W. Dodge (This initial collection of data eventually became the $\mathrm{NC}^{3}$ database). This space data is then applied to the space type LPDs to create whole building lighting power densities that can be reasonably applied to typical national new building construction. The drawings from F.W. Dodge used to develop the space type data were chosen to represent the six regions covering the entire continental U.S. using the following criteria:

- Listed cost estimates for the chosen buildings were close to the average cost estimate for that building type as provided by F.W. Dodge. This provided a rough measure that the building size is neither excessively large nor small.

- The one-line description matches the building type as closely as possible, avoiding "mixed" occupancy buildings. Buildings that are obvious alterations or strict remodels are avoided. This provides the cleanest building type data possible.

- Most buildings are chosen with 1996 through 2001 drawing dates.

The current database of buildings used in the whole building LPD development includes 246 (151 of these are part of the current NC3 database) complete buildings from across the country. Each individual building type LPD value is represented by typically 3 to 8 buildings and as high as 40 for some.

For each of the drawing sets, a detailed take-off of the building square footage on a space-by-space basis is completed. These take-offs break the total square footage for each building into 25 or more commonly used building spaces and up to 50 or more specific building type spaces. The take-off square footage data for each building is summed by space type and building total. These space and building totals are used to calculate the percentage of each space type within the building. The space type percentages are matched to the specific application model (described previously) that fits that space type description for that building type. Using these space and model matches, a weighted average LPD can be derived for that building. The building LPDs can then be weighted among themselves depending on the estimated frequency of that building design. In this analysis, because the drawings were chosen randomly, the individual building LPDs within a specific building type are given equal weight. The end results of these calculations is a weighted average building type LPD for a set of whole building types to be used for compliance in the standard

It is understood that the use of as few as three or four sets of drawings (in some cases) for one building type cannot be considered a statistically valid sample. However, the wide variety of building designs makes the determination of a statistically valid sample very difficult and at best, it is likely to be a very 
large number - much beyond the scope or practicality of the development of most energy standards. The use of a small sample of randomly chosen buildings from a well recognized and documentable source of building drawings is the best available basis for this kind of analysis. While lighting design is by nature somewhat subjective, the use of actual designed building spaces and lighting models provides the most accurate and defensible method for developing whole building energy-efficiency standards.

\section{1-(2004) Lighting Power Density Development}

The development of the proposed 90.1-2004 LPD values uses the same methodology as the 1999 and 2001 versions but incorporates a complete update of all of the model inputs. The initial review of the models was prompted by the publication of the IESNA $9^{\text {th }}$ Edition Handbook which includes a completely revised set of light level recommendations - an important component of the LPD models. The review also incorporated recent research data on fluorescent fixture light loss factors and space type characteristics of new commercial construction. As the review progressed, all remaining inputs were reviewed and updated against current knowledge of lighting principles, design applications and efficient equipment availability. Details of each review and update are as follows:

- Light level inputs. Each of the 124 individual space models was reviewed and both task lighting and general lighting levels compared with the new IESNA $9^{\text {th }}$ Edition recommendations. Values were adjusted where necessary and where exact matches were not available, professional consensus was applied to derive appropriate values. This review also revisited the percentage split of task versus general lighting, making changes where appropriate considering current commercial use of space.

- Applied lighting technologies. Each of the 124 individual space models incorporates up to three specific lighting technologies represented by generic luminaire (fixture) types. For each model, these were reviewed to ensure their applicability based on current energy efficient and lighting quality design practice. Changes were made to more appropriate technologies where current design practice warranted.

- Lighting technology application formula. The initial formula used to weight the power density needs of the lighting technologies (up to three) for each space model was based on the wattage of each technology. This method allocated energy needs reasonably well for consistent types of technologies (i.e., all fluorescents) but was not as accurate for mixed sets of technologies. The formula was revised to directly weight the technologies by lumen output of each technology providing a more accurate assessment of power needs for all technology types.

- Lighting technology efficiencies and light loss factors. Each of the 35 generic luminaire/fixture types incorporates lamp technology efficiencies as well as light loss factors relating to lamp lumen depreciation, luminaire/fixture dirt depreciation, and room dirt depreciation. The lamp efficiency for each of the 35 types was reviewed against current technology and revisions made to reflect currently available products. The review also prompted some updates to the associated lamp lumen depreciation factors. A recent study on luminaire dirt depreciation was used to update these values for most fluorescent luminaire types. The luminaire dirt depreciation value for all remaining types was reviewed against the latest IESNA manual data and revisions made where appropriate. Room dirt depreciation values were reviewed but no changes made. 
- Luminaire/Fixture data. The generic luminaire type performance characteristics (efficiency, etc.) are based on the actual tested characteristics of over 240 specific luminaire products. These were reviewed and found to be generally still applicable. New luminaire data was incorporated for one downlight model to more accurately represent current application and one additional luminaire type (industrial fluorescent) was added.

- Whole building LPD development data. The initial (published) whole building values are derived by applying the 124 space models to detailed interior space type data on a set of 95 buildings. An advanced set of 151 additional buildings has been added to form a detailed building interior space data set of 246 buildings. This new data set has been used to develop the proposed set of whole building values.

An estimate of the potential effect on energy efficiency from the adoption of these new numbers compared to the current published numbers was initially a $29 \%$ reduction in building type weighted LPD (based on 1995 CBECS building type square footage data). A recent revision of that calcula tion using better new construction data from F.W. Dodge (for year 2001) produced a more relative value of $25 \%$. Actual realized energy savings will depend on many factors including current lighting design practice (is it already better than the current standard?) and adoption of the standard (who will require and actually enforce it?). The natural variability of lighting design makes estimates of potential energy savings difficult. The $25 \%$ reduction in building type weighted LPD only provides a consistent relative comparison between the two sets of standards values. What this value strictly means is: "The expected lighting power density between a "nationally representative" group of buildings (F.W. Dodge 2001 new construction floor space weights were used as a proxy for U.S. building trends) designed EXACTLY to the 90.1-2001 LPD values and a similar group of buildings designed EXACTLY to the 90.1-2004 LPD values would be $25 \%$."

The term "exactly" is used above, because a building, which obviously has lower LPDs, is also deemed to "meet" the standard in terms of compliance. Also note that the above description talks about lighting power density and not overall lighting energy. Different building types received different reductions in overall lighting power density. While the overall average LPD reduction was $25 \%$, to the extent that there are differences in total hours of operation between building types, the change in total lighting energy may differ from the average change in building lighting power density.

The $25 \%$ figure was developed within the 90.1 Committee to address their interest in knowing the expected change between Standard's levels (current and proposed). It was and still is extremely difficult to assess actual current lighting application and projected application of these ASHRAE LPD numbers. The 90.1-1999/2001 lighting levels (used to derive this 25\% relative increase) are not known to be representative of "typical" current practice. We know from actual data that many building designs already show lower building lighting levels than the ASHRAE 90.1-1999/2001 levels and some are lower than the ASHRAE 90.1-2004 values. On the other hand there are other new buildings that do not meet the ASHRAE 90.1999/2001 levels. Where this mix averages out over the whole building spectrum is unknown.

The potential $25 \%$ change is the combined result of all of the updates made to the LPD models. Approximately $3 \%$ of this potential energy change is attributed to the update of the lamp lumen depreciation data. Another $6 \%$ can be attributed to updates to the light source efficacies (lamp and ballast technology efficiencies). The remaining $16 \%$ is from the combined updates of new IESNA light 
levels, allocation lighting needs to task and general lighting, and assignment of appropriate lighting technologies and luminaries to each model.

The contribution in potential energy savings also varies by building type based the actual change in building LPD as well as the fraction of total building stock represented by that building type. The individual whole building LPD values, while averaging around $25 \%$, varied from a $7 \%$ increase for performing arts theatres (the only increase) to a 50\% reduction for Motels. 


\section{Appendix B}

\section{Distributions of Current Practice Data}




\section{Appendix B Distributions of Current Practice Data}

The following bar plots represent the distribution of individual building LPDs in the $\mathrm{NC}^{3}$ data set. The appropriate building type LPD requirement value for the 90.1-1999 and 90.1-2004 (proposed) standards and a point 25\% (50\% for Warehouse) below 90.1-1999 are shown as lines within each plot. These plots provide a graphical view of the potential effect of current practice on compliance with codes and a possible tax deduction.

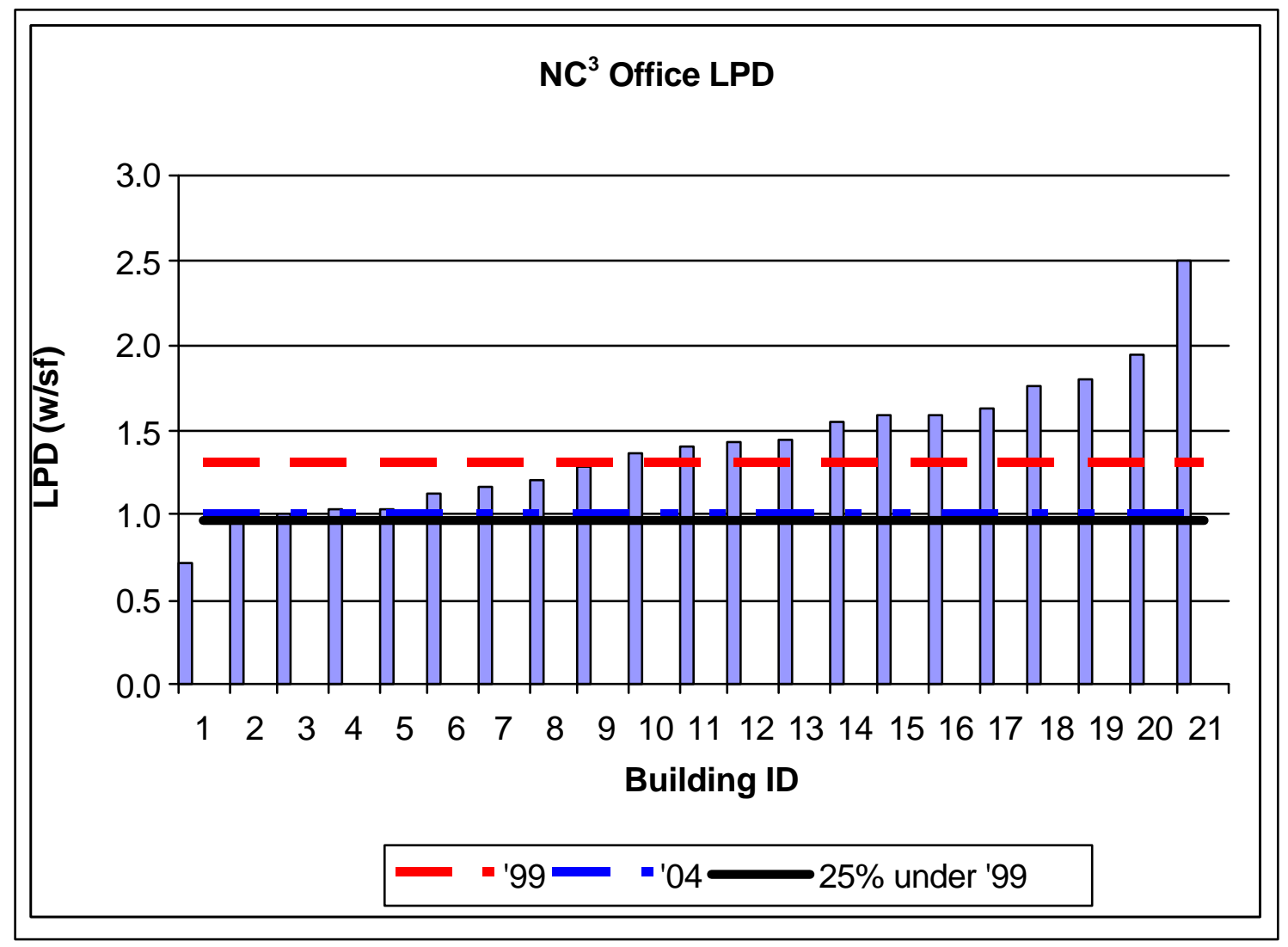

B.1 

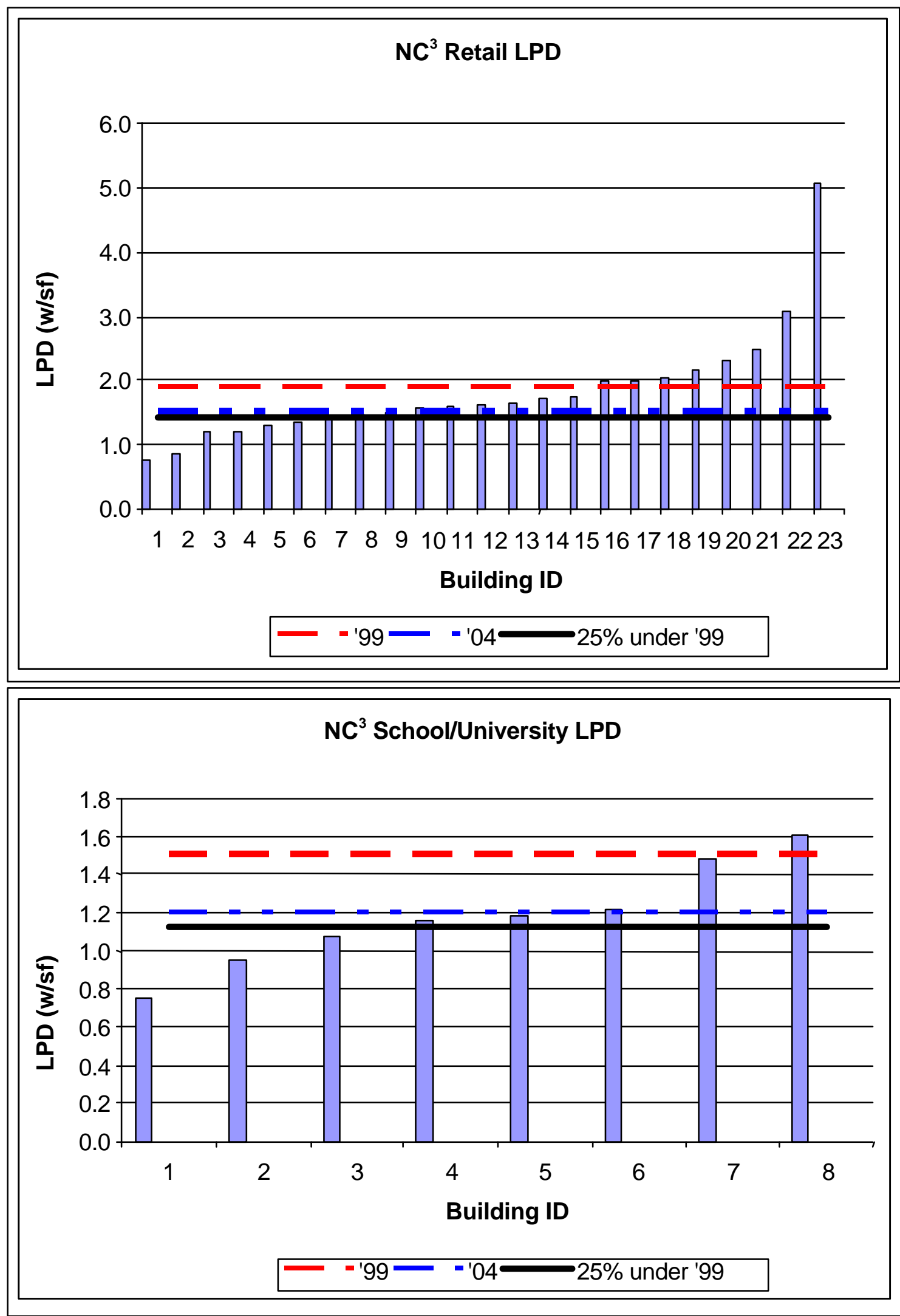


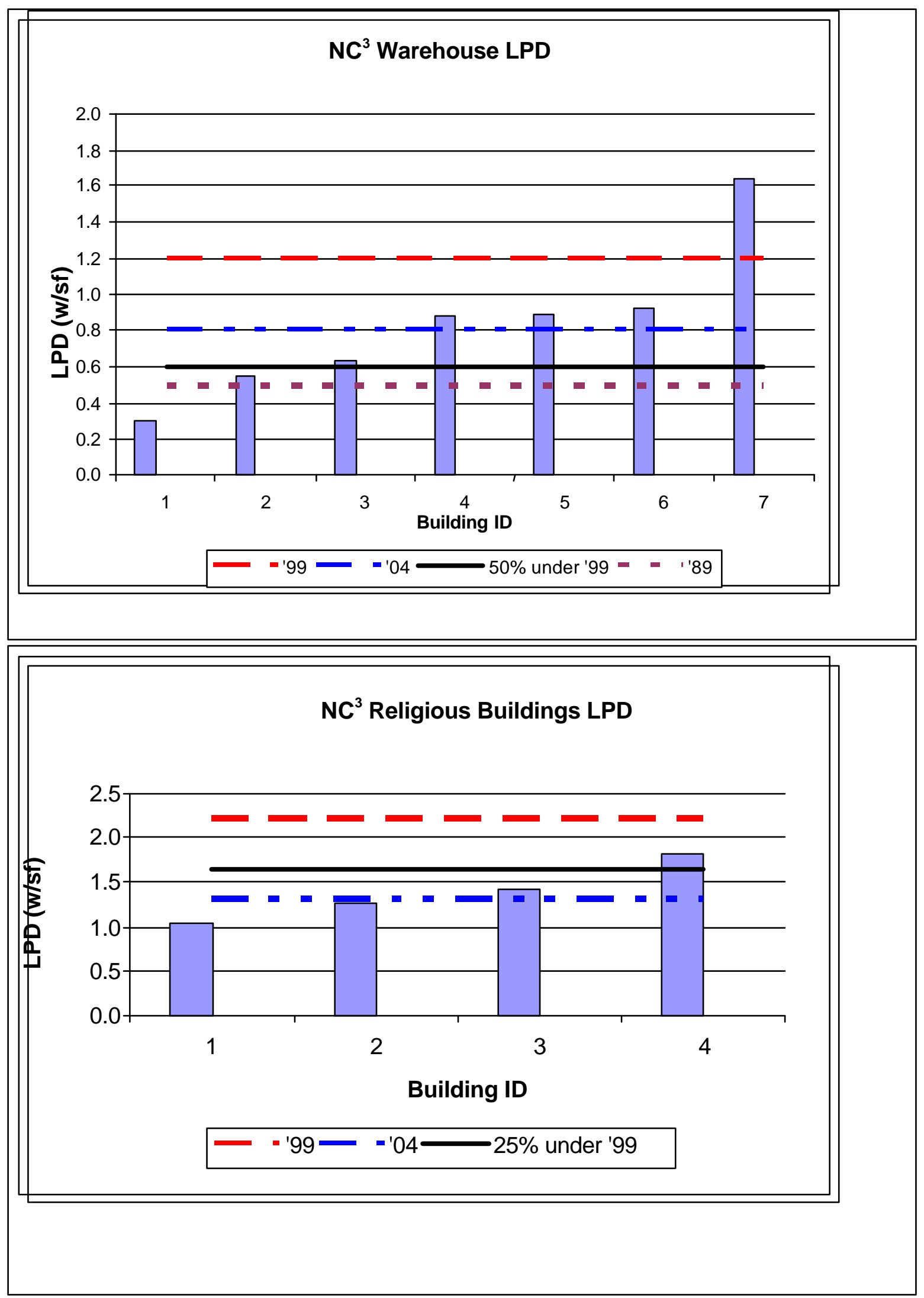

B. 3 


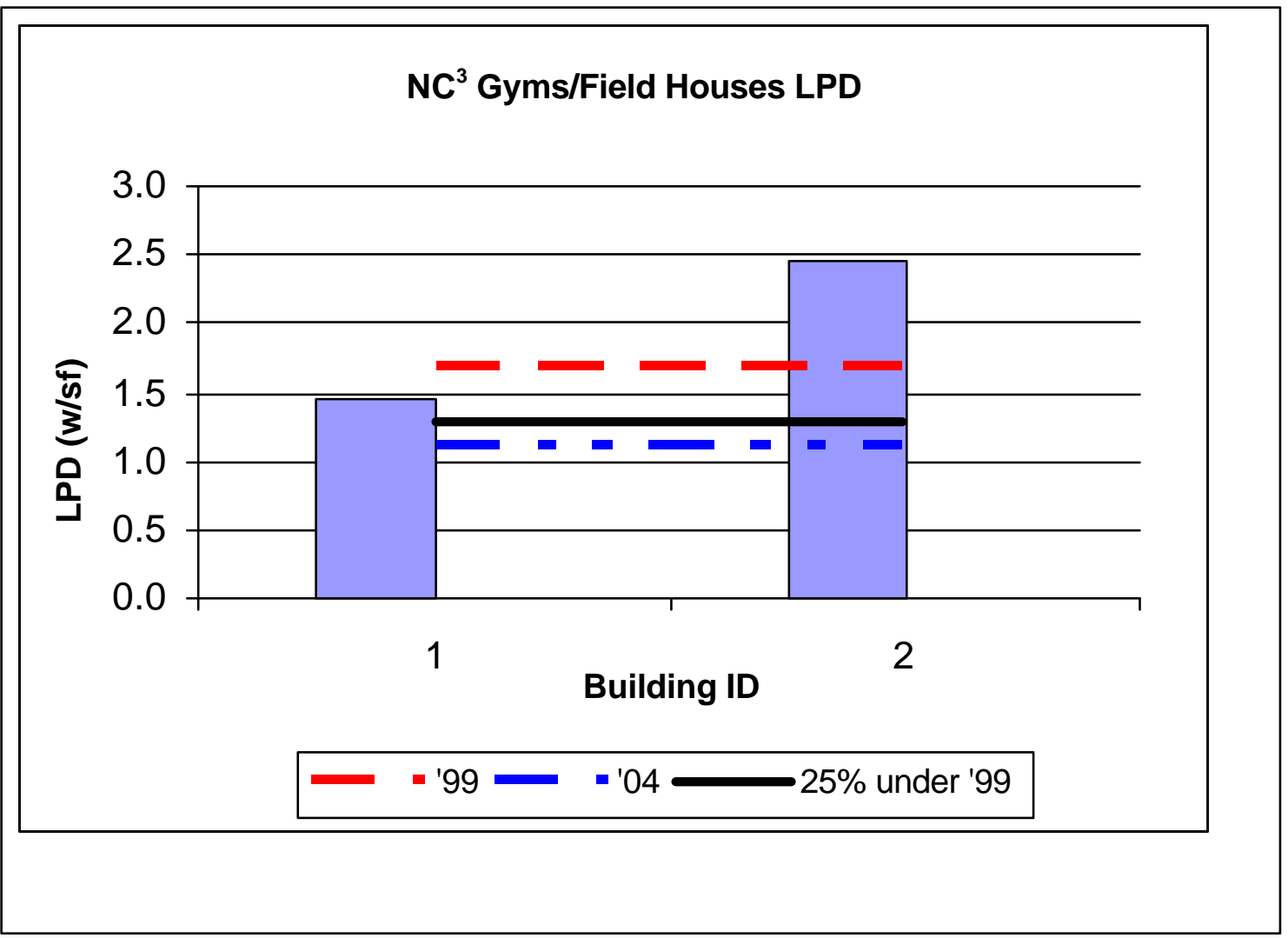

B. 4 


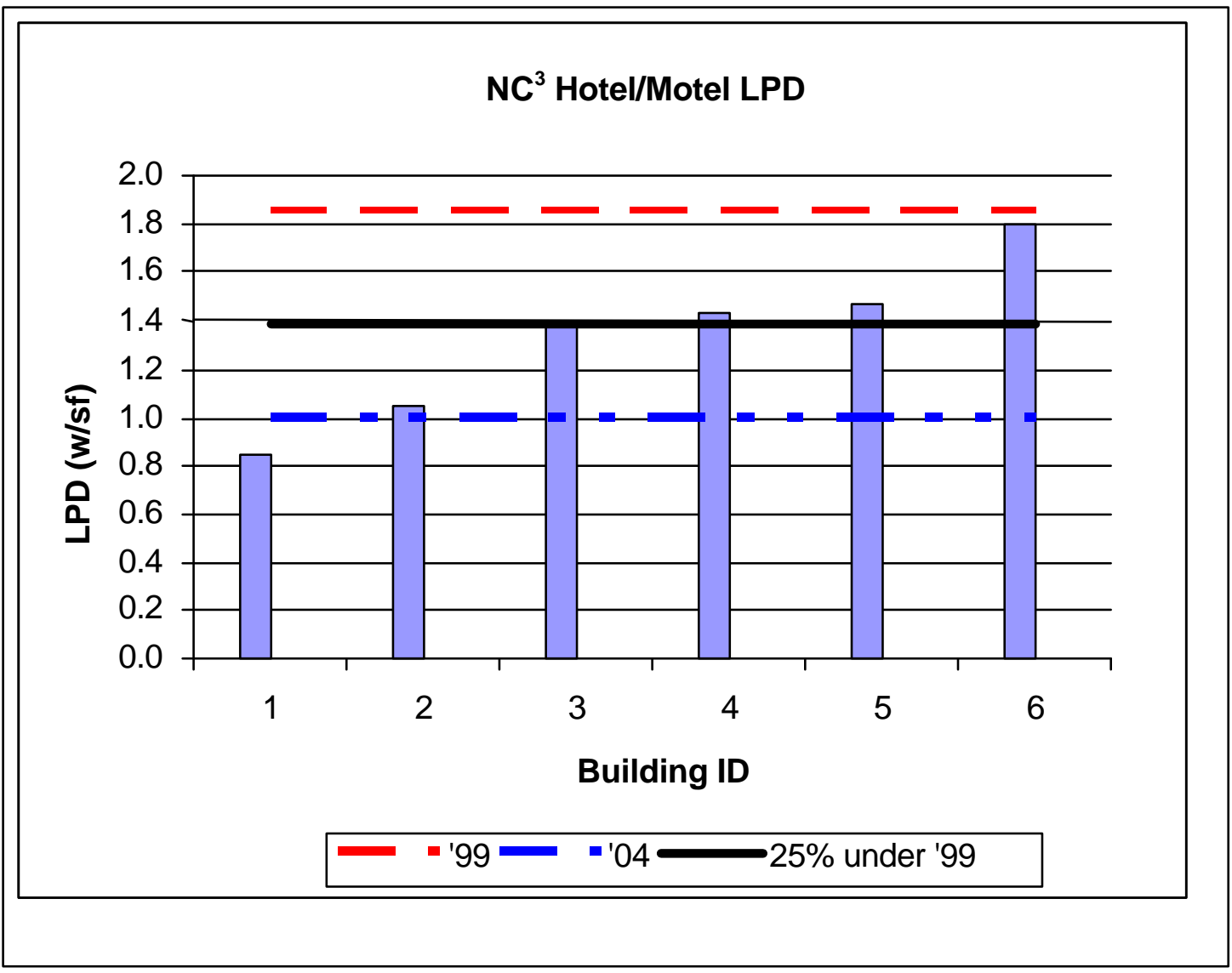

B. 5 
Appendix C

\section{Projected New Floor Space by State}




\section{Appendix C Projected New Floor Space by State}

The estimates and projections of new floor space by State are developed from a number of sources. Essentially, we follow a top-down, multi-stage process of allocating national-level estimates to States.

The year 2001 is taken as the starting point for the procedure. A national estimate of new commercial construction is taken from recent PNNL work that has developed historical floor space estimates consistent with the various Commercial Building Energy Conservation Survey (CBECS). Based upon the 1989 and 1992 building definitions in the CBECS $^{\text {d }}$, floor space additions in 2001 are estimated to be 2.0 billion square feet nationwide.

At the next level, an allocation is made to the census division level. The commercial module of the National Energy Modeling System (NEMS) generates estimates of new floor space by census division. We used unpublished output from the 2002 Annual Energy Outlook (AEO) to perform this allocation. ${ }^{\text {e }}$

The CBECS and the AEO provide no data that is disaggregated to the State level. We used value of new construction by State to allocate the estimates (and projections) of floor space within each census division. At present, we are using U.S. Census Bureau information on the value of new nonresidential construction by State. In an effort to smooth out year-to-year fluctuations, the State-level data are averaged over a 5-year interval, 1995-1999.

Because the prices for materials and labor vary across States, we attempt to adjust the Census data for this variation before the allocation of census division floor space is undertaken. Cost indexes for each State are developed from data published by R.S. Means. These cost indexes are divided into the construction value data as a way of producing numbers that better reflect the quantity (square footage) of new construction.

The projections of new floor space additions beyond 2001 are keyed to the national level projections. National level census data, in terms of 1996 constant dollars, are used to extrapolate the 2001 estimate of new floor space. Compared to 2001, construction activity fell by about $4 \%$ in 2002 . Based upon census

\footnotetext{
${ }^{\mathrm{d}}$ The 1989 and 1992 CBECS include parking garages and multibuilding facilities located on manufacturing sites. Work planned for FY 2004 may attempt to develop estimates that are consistent with the most recent CBECS that exclude these buildings. However, these buildings are covered by energy codes, especially those on manufacturing sites, and thus the current definition is appropriate for this analysis.

${ }^{\text {e}}$ EIA substantially changed the building lifetimes for the AEO 2003, which has the effect of increasing the projected new construction substantially from prior AEOs. In a memorandum sent to EERE's Michael McCabe and John Millhone in May 2003, we argue that these more recent projections should not be used in EERE analytical efforts.
} 
data for the first 6 months of 2003, we expect some further decline in 2003 of 2 to $3 \%$. The projections of total new floor space are assumed to gradually rise to the 2001 level ( 2.0 billion square feet) by $2005 .{ }^{\mathrm{f}}$ The State level projections are based on the allocation procedures using the 2002 AEO census division projections and the State-level shares based upon the adjusted census expenditures data.

\footnotetext{
${ }^{\mathrm{f}}$ Nonresidential construction is more related to the level of economic activity than the residential sector and, thus, does not respond as sharply to the level of interest rates. Thus, nonresidential construction has fallen in the past two years, especially in the private sector. While we used the AEO as a means of allocating new floor space to the census divisions, we did not believe the projected levels of national construction were plausible. The 2002 AEO showed total new floor space peaking in 2001 and declining thereafter in each year through 2009.
} 
Appendix D

\section{Other Current Practice Data Sources}




\section{Appendix D Other Current Practice Data Sources}

Two additional data sets were considered for use in this analysis. The Ecotope study: "Survey of Energy Efficiency in Seattle's New Non-Residential Buildings: 1995-2000" provides LPD values for sample buildings across several building types in the Seattle area. The RLW Analytics study: "California StateLevel Market Assessment and Evaluation Study: Non-Residential New Construction Baseline Study" provides similar LPD data for California.

These data sets present building information on buildings constructed in the late 1990s. The data was collected through a combination of take-offs from as-built plans and partialor complete audits and surveys. These data sets include assessments of HVAC equipment and systems, controls, window efficiency, and lighting installations. The raw audit data for the buildings in these data sets were not available for review, so the values provided in the reports are considered here without verification of completeness or accuracy

Advantages of these data sets include:

- Relatively new construction status

- Published survey data

Potential disadvantages include:

- West Coast samples only - not representative of national practice.

- Samples are from generally progressive energy States with their own unique codes - not representative of national code adoption

These data sets can be used as a reality check of the $\mathrm{NC}^{3}$ data that was used in the analysis. For comparison, the fractions of buildings in each sample that could be eligible for a partial or complete tax deduction were calculated. These are compared with the corresponding $\mathrm{NC}^{3}$ fractions (where there is a match) in Table D.1.

Table D.1 Comparison of Potential Free Rider Percentage

\begin{tabular}{|l|c|c|c|}
\hline & \multicolumn{4}{|c|}{ Percent of Buildings With LPDs Below Tax Threshold } \\
\hline Building Type & $\mathrm{NC}^{3}$ (National) & Ecotope (WA) & RLW (CA) \\
\hline Office & $5 \%$ & $29 \%$ & $9 \%$ \\
\hline Retail & $26 \%$ & $11 \%$ & $17 \%$ \\
\hline School & $38 \%$ & $63 \%$ & $13 \%$ \\
\hline Warehouse & $29 \%$ & $33 \%$ & $27 \%$ \\
\hline
\end{tabular}

The comparison shows a wide range of potential free riders varying among building types. For The Washington sample, retail buildings appear to have fewer free riders (and therefore generally higher current LPDs) than the national average. All other building types appear the opposite, representing generally lower LPDs than the nation. For the California sample, offices appear to have slightly higher 
free riders and therefore generally lower LPDS than the Nation, but all other building types appear to have higher LPDs.

Differences in these three samples may be affected by the difference in energy code application. For comparison, Table D.2 shows the difference between Washington code (WSEC 1997) LPD levels and the corresponding (national) code in effect for the $\mathrm{NC}^{3}$ sample (ASHRAE 90.1-1989). The \% difference values here generally follow the potential free-rider trends shown in Table D.1. Lower Washington code LPD requirements tend to follow the generally lower LPDs associated with higher free-rider potential shown in Table D.1. The exception here is the retail sample where the opposite is found. This helps explain why the values differ from the national sample, a partial reason why these data cannot be considered representative of the nation.

Table D.2 Comparison of Washington WSEC and ASHRAE Energy Code LPDs

\begin{tabular}{|l|c|c|c|}
\hline Building Type & WSEC 1997 & ASHRAE 90.1-1989 & \% Difference \\
\hline Office & 1.13 & 1.7 & $-34 \%$ \\
\hline Retail & 2.08 & 2.7 & $-23 \%$ \\
\hline School & 1.14 & 1.9 & $-40 \%$ \\
\hline Warehouse & 0.5 & 0.6 & $-17 \%$ \\
\hline
\end{tabular}

A similar comparison is made for the California Title 24 code in Table D.3. However, in this case the apparent higher current LPDs inferred from Table D.1 do not readily correspond with the slightly lower LPDs required by the California code.

Table D.3 Comparison of California Title 24 and ASHRAE Energy Code LPDs

\begin{tabular}{|l|c|c|c|}
\hline Building Type & Title 24 1998 & ASHRAE 90.1-1989 & \% Difference \\
\hline Office & 1.2 & 1.7 & $-29 \%$ \\
\hline Retail & 1.7 & 2.7 & $-37 \%$ \\
\hline School & 1.4 & 1.9 & $-26 \%$ \\
\hline Warehouse & 0.7 & 0.6 & $+17 \%$ \\
\hline
\end{tabular}




\section{Distribution}

No. of

$\underline{\text { Copies }}$

\section{OFFSITE}

3 Michael McCabe

U.S. Department of Energy

EERE-Building Technologies

Program (EE-2J)

1000 Independence Ave., S.W.

Washington, DC 20585

2 John D. Ryan

U.S. Department of Energy

EERE-Building Technologies

Program (EE-2J)

1000 Independence Ave., S.W.

Washington, DC 20585

Ed Pollock

U.S. Department of Energy

EERE-Building Technologies

Program (EE-2J)

1000 Independence Ave., S.W.

Washington, DC 20585

Qonnie Laughlin

U.S. Department of Energy

EERE-Building Technologies

Program (EE-2J)

1000 Independence Ave., S.W.

Washington, DC 20585

Sam Baldwin

U.S. Department of Energy

EERE-Office of Planning, Budget

Formulation, and Analysis (EE-3B)

1000 Independence Avenue, S.W.

Washington, DC 20585
No. of

$\underline{\text { Copies }}$

Jerry Dion

U.S. Department of Energy

EERE-Office of Planning, Budget Formulation, and Analysis (EE-3B)

1000 Independence Avenue, S.W.

Washington, DC 20585

Phil Patterson

U.S. Department of Energy

EERE-Office of Planning, Budget Formulation, and Analysis (EE-3B)

1000 Independence Avenue, S.W.

Washington, DC 20585

Mary Beth Zimmerman

U.S. Department of Energy

EERE-Office of Planning, Budget Formulation, and Analysis (EE-3B)

1000 Independence Avenue, S.W.

Washington, DC 20585

Ronald E. Majette

U.S. Department of Energy

EERE-Building Technologies

Program (EE-2J)

1000 Independence Ave., S.W.

Washington, DC 20585

Ed Barbour

Navigant Consulting

1801 K Street, NW

Suite 500

Washington, D.C. 20006

Distr.1 
No. of

Copies

$\underline{\text { ONSITE }}$

2 DOE Richland Operations Office

Kim Williams $\quad$ K8-50

38 Pacific Northwest National Laboratory

D. M. Anderson K5-06

D. B. Belzer K5-06

K. A. Cort K5-06

J. A. Dirks K6-10

D. J. Hostick K5-06

10 S. C. McDonald BWO

A. K. Nicholls BWO

2 E. E. Richman K5-16

B. F. Saffell K5-02

L. J. Sealock K5-02

10 D. Winiarski K5-06

D. Shankle K6-52

S. A. Shankle K5-16

T. M. Weber K5-06

5 Information Release Office K1-06

Distr.2 